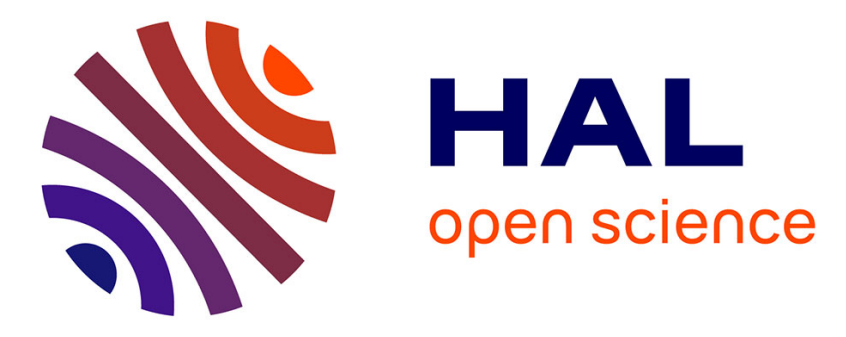

\title{
Diblock Copolymer Core-Shell Nanoparticles as Template for Mesoporous Carbons: Independent Tuning of Pore Size and Pore Wall Thickness
}

Vitalii Tkachenko, Camelia Matei Ghimbeu, Cyril Vaulot, Ludovic Josien, Loïc Vidal, Julien Poly, Abraham Chemtob

\section{To cite this version:}

Vitalii Tkachenko, Camelia Matei Ghimbeu, Cyril Vaulot, Ludovic Josien, Loïc Vidal, et al.. Diblock Copolymer Core-Shell Nanoparticles as Template for Mesoporous Carbons: Independent Tuning of Pore Size and Pore Wall Thickness. Langmuir, 2019, 35 (49), pp.16324-16334. 10.1021/acs.langmuir.9b02994 . hal-02407827

\section{HAL Id: hal-02407827 \\ https://hal.science/hal-02407827}

Submitted on 12 Dec 2019

HAL is a multi-disciplinary open access archive for the deposit and dissemination of scientific research documents, whether they are published or not. The documents may come from teaching and research institutions in France or abroad, or from public or private research centers.
L'archive ouverte pluridisciplinaire HAL, est destinée au dépôt et à la diffusion de documents scientifiques de niveau recherche, publiés ou non, émanant des établissements d'enseignement et de recherche français ou étrangers, des laboratoires publics ou privés. 


\section{Diblock Copolymer Core-Shell Nanoparticles as}

\section{Template for Mesoporous Carbons: Independent}

\section{Tuning of Pore Size and Pore Wall Thickness}

Vitalii Tkachenko, ${ }^{1,2}$ Camélia Matei Ghimbeu, ${ }^{1,2}$ Cyril Vaulot, ${ }^{1,2}$ Ludovic Josien, ${ }^{1,2}$ Loïc Vidal, ${ }^{1,2}$ Julien Poly ${ }^{1,2} *$ and Abraham Chemtob $b^{1,2}$ *

${ }^{1}$ Université de Haute-Alsace, CNRS, IS2M UMR7361, F-68100 Mulhouse, France

${ }^{2}$ Université de Strasbourg, France

\section{ABSTRACT}

Latex templating using core-shell particles represents a unique opportunity to design mesoporous carbons with a high level of control on textural properties. This new class of organic colloid templates is synthesized by polymerization-induced self-assembly (PISA) in which a solvophilic poly(hydroxyethyl acrylate) (PHEA) homopolymer is chain extended with a solvophobic polystyrene (PS) via a photomediated reversible-addition fragmentation-transfer (RAFT) polymerization. The resultant PHEA- $b$-PS diblock copolymer nanoparticles exhibit a PS core stabilized by a PHEA shell, with two blocks characterized by a low molecular weight 
dispersity (1.1-1.3) and an adjustable degree of polymerization (DP). The core-shell structured nanoparticles are used as soft template for the formation of mesostructured carbons from phloroglucinol and glyoxylic acid in methanol solution. A micro- and mesostructured cellular foam is obtained having uniform, interconnected and narrowly distributed mesopores ranging between 15 and $30 \mathrm{~nm}$ in diameter, a specific surface area up to $719 \mathrm{~m}^{2} \mathrm{~g}^{-1}$, and a total pore volume of $0.4-1.3 \mathrm{~cm}^{3} \mathrm{~g}^{-1}$. The mesopore size can be controlled by adjusting the diameter of the PS core $(16-29 \mathrm{~nm})$, while the wall thickness can be tailored independently by varying the size of the solvated PHEA shell $(5-25 \mathrm{~nm})$. An increase of PHEA block's DP from 25 to 85 gradually extends the stabilizing shell dimension, thus increasing the wall thickness up to $10 \mathrm{~nm}$, and causing the shift from interconnected to isolated mesopores. By comparison, much thinner walls $(2-3 \mathrm{~nm})$ are obtained with conventional latex templates such as polystyrene nanoparticles or colloidal silica. Decreasing PHEA DP to 17 induces the formation of copolymer vesicles that can be used as template to create mesoporous carbons with non-spherical mesopores. 


\section{INTRODUCTION}

Latex templating has proven very successful for designing macroporous materials with pore sizes ranging from 50 nanometers to a few micrometers. ${ }^{1-3}$ Conversely, this route has been used only to a limited extent for the preparation of mesoporous materials with smaller pore sizes (between $2 \mathrm{~nm}$ and $50 \mathrm{~nm}$ ), in particular if compared to the countless reports involving a polymerization within surfactant liquid crystalline (LC) phases. ${ }^{5,6}$ Despite the enormous diversity of polymers, latex templating essentially relies on standard monodisperse polystyrene (PS), ${ }^{7-10}$ poly(methyl methacrylate) ${ }^{11}$ or poly(ionic liquid) ${ }^{12}$ nanoparticles stabilized by adsorbed molecular ionic surfactant. Their use has made possible the synthesis of carbon $^{7,8,10,11}$ or silica $^{4,9,12}$ mesoporous materials with ultralarge-pores $(30-50 \mathrm{~nm})$, difficult to achieve with existing conventional methods. Unlike inorganic nanoparticles, organic colloids can also be easily removed by calcination at moderate temperature $\left(300-400{ }^{\circ} \mathrm{C}\right)$. Despite these advantages, latex templating suffers from two major drawbacks. Firstly, their use for mesoporous materials' synthesis necessitates particles with a diameter smaller than $50 \mathrm{~nm} \cdot{ }^{13}$ However, only a handful of polymerization processes in dispersed media can achieve this size range, including microemulsion polymerization. ${ }^{14}$ Despite a significant utilization of this technique in the literature, ${ }^{7,11}$ low monomer content $(5-10 \mathrm{wt} \%$ of the total mass) and much higher surfactant concentration $(\sim 10 \mathrm{wt} \%)$ are required in a microemulsion polymerization compared to its

analogue in emulsion $(\sim 1-2 \mathrm{wt} \%)$ due to the necessity of stabilizing a larger interfacial area. ${ }^{15}$ This restricts the potential use of microemulsion-polymerized particles in a template synthesis since high particles contents and low surfactant levels are desirable for this application. A second limitation of colloidal templating is that the latex spheres are regarded only as spatial fillers: ${ }^{16}$ the polymerizing medium acts as matrix, whose growth at the interface simply "coats" the 
template. It follows that the role played by latex surface properties is often overlooked, although they are the key to matrix/template compatibility, pore architecture control and pores' interconnectivity. This aspect has been insufficiently researched because it remains very challenging to adjust precisely the composition and the dimension of organic particles' surface. ${ }^{4}$

In order to expand the usage of latex templating for mesoporous materials, new synthetic methods are therefore needed to create organic colloids with tunable sizes, small diameters $(<50$ $\mathrm{nm}$ ) and well-defined surface properties. These developments are of a major importance for mesoporous carbons since the design of pores larger than $10 \mathrm{~nm}$ is difficult to obtain by using classical silica hard template and/or surfactant soft template approaches. ${ }^{17,18}$ For many applications, large mesopores are known to improve the accessibility and the transport efficiency of large molecules such as biomacromolecules, organic molecules, bulky dyes and viruses. ${ }^{19-21}$ Moreover, large mesopores can be employed as nanoreactors to confine metal-based nanoparticles, drug and gene molecules, acting as catalyst, energy storage material, adsorption site or biomedical carrier, leading thus to hybrid materials with improved performances. ${ }^{22-24}$ Currently, most ultra-large mesoporous carbons were synthesized using LC mesophases based on specific amphiphilic poly(ethylene oxide)-based block copolymers. ${ }^{25-27}$ Thus, polymer nanoparticles could open new avenues for mesoporous carbons with ultra-large and tunable pore sizes and featuring an open porosity.

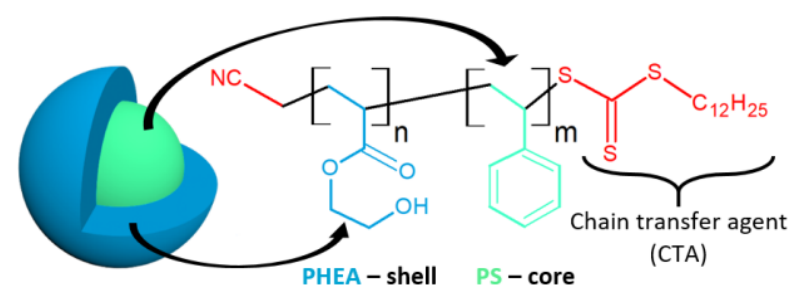

Figure 1. Poly(hydroxyethyl acrylate)- $b$-polystyrene (PHEA-b-PS) core-shell nanoparticles with a diameter ranging from 20 to $40 \mathrm{~nm}$ synthesized via PISA. The chain ends result from the RAFT chain transfer agent (S-cyanomethyl-S-dodecyltrithiocarbonate) used to mediate the controlled radical polymerization. 
Herein, we report the use of spherical core-shell nanoparticles based on an amphiphilic diblock copolymer to template mesoporous carbons. Narrowly distributed poly(hydroxyethyl acrylate)- $b$ polystyrene (PHEA- $b$-PS) core-shell nanoparticles with diameters ranging from 20 to $40 \mathrm{~nm}$ (Figure 1) were synthesized by polymerization-induced self-assembly (PISA). ${ }^{28}$ Extensively investigated over the last 10 years, PISA represents an efficient and versatile route to block copolymer nano-objects. ${ }^{29,30}$ In particular, PISA has proven successful to create sub-50 nm nanoparticles with a core-shell morphology. ${ }^{31,32}$ In addition to having a suitable diameter range and size distribution, our diblock copolymer nanoparticles do not require additional surfactant since stabilization is ensured by PHEA chains. Unlike electrostatic stabilization, such steric stabilization leads to a more robust template able to disperse in various organic monomer solutions. ${ }^{33}$ Recently, a PISA templating approach was described involving the immobilization of reactive precursors within the shell of the nano-objects to yield inorganic hollow nanoparticles. ${ }^{34}$ Our process resulting in mesoporous carbon materials is significantly different. Typically, our core-shell nanoparticles were dispersed in a mixture of phenolic resin precursors (phloroglucinol and glyoxylic acid). ${ }^{35,36}$ The solvophilic PHEA block acts as steric stabilizer forming an outer shell in contact with the polymerizing medium. The hydroxyl groups of PHEA chains favor hydrogen bonds and even covalent coupling with the phenolic resin. The particle core is made up of the phase segregated solvophobic PS block. After polymerization and solidification of the phenolic polymer network, template decomposition and carbonization are performed in a single step to generate a mesoporous carbon structure. PHEA and PS form two separated shell and core domains, respectively, whose sizes can be finely and independently adjusted by controlling the degree of polymerization (DP) of the two polymer blocks. As a result, such core-shell copolymer particles have a well-defined structure, particularly as regards surface 
composition. This makes PISA-derived particles a much more versatile and complex template than a conventional latex. We demonstrate here that pore size can be varied within the mesopore range by changing the PS core diameter, while the wall thickness can be controlled by the extent of the stabilizing PHEA shell, which delimitates two neighboring particles. Additionally, mesoporous carbons with original pore topology can be achieved starting from non-spherical PISA particles such as vesicles.

\section{EXPERIMENTAL SECTION}

\section{MATERIALS}

Hydroxyethyl acrylate (HEA, TCI, > $96 \%$ ) was purified by passing through a basic alumina column (Sigma) prior to use. Styrene (Sigma, $\geq 99 \%$ ) and 1,4-dioxane (Sigma, 99.5\%) were distilled under reduced pressure over $\mathrm{CaH}_{2}$ prior to use. Methanol (Fischer Chemical; $\geq 99 \%$ ), S-cyanomethyl-S-dodecyltrithiocarbonate (TTC; Sigma, $98 \%$ ), phloroglucinol (Sigma, $\geq 99 \%$ ), glyoxylic acid (Sigma, $\geq 99 \%$ ), diethyl ether (Sigma, $\geq 99 \%$ ), sodium dodecyl sulfate (SDS, TCI, $>97 \%$ ), ammonium persulfate (Sigma, $\geq 98 \%$ ) and LUDOX® AS-40 colloidal silica (Sigma, 40 wt. \% dispersion in $\mathrm{H}_{2} \mathrm{O}$, average diameter: $22 \mathrm{~nm}$ ) were used as received.

\section{SYNTHESES}

Photomediated RAFT polymerization of HEA in solution (ex. PHEA 25 -TTC). In a typical synthesis, HEA (4.04 g, $34 \mathrm{mmol})$, TTC (0.396 g, $1.2 \mathrm{mmol})$ and 1,4-dioxane (12.16 g) were charged into a $30 \mathrm{~mL}$ Schlenk tube equipped with a stirring bar. The mixture was degassed by three freeze-pump-thaw cycles, then purged under nitrogen. The tube was then placed in a preheated oil bath at $25{ }^{\circ} \mathrm{C}$ and irradiated during $5 \mathrm{~h}$ in an immersion type photoreactor 
containing a blue LED spot light $\left(\lambda=472 \mathrm{~nm}, 547 \mathrm{~mW} \mathrm{~cm}^{-2}\right)$. After $5 \mathrm{~h}$ (HEA conversion of 58 $\%$ ), the polymer PHEA $_{25}$-TTC was recovered by precipitation into $200 \mathrm{~mL}$ of diethyl ether, then dried under vacuum overnight to give $\sim 1.5 \mathrm{~g}$ of purified macrophotoinitiator. The syntheses involving PHEA $_{\mathrm{n}}$-TTC of different lengths were performed at the same monomer/solvent weight ratio of $1 / 3$.

Synthesis of PHEA-b-PS diblock copolymer particles via photomediated dispersion PISA of styrene (ex. $\left.\mathrm{PHEA}_{25}-b-\mathrm{PS}_{118}\right)$. In a typical synthesis, macrophotoinitiator $\mathrm{PHEA}_{25}$-TTC (0.266 g, $0.082 \mathrm{mmol})$, styrene $(1.721 \mathrm{~g}, 16.5 \mathrm{mmol})$ and a methanol/water mixture $(8.18 \mathrm{~g} / 0.43 \mathrm{~g}, 95 / 5$ wt/wt \%) were charged into a Schlenk tube equipped with a stirring bar. The mixture was degassed by three freeze-pump-thaw cycles before being purged by nitrogen. The tube was then placed in a pre-heated oil bath at $35{ }^{\circ} \mathrm{C}$ and irradiated during $70 \mathrm{~h}$ in an immersion type photoreactor $\left(\lambda=472 \mathrm{~nm}, 547 \mathrm{~mW} \mathrm{~cm}^{-2}\right)$. The polymer content in the final dispersion was 10.5 wt.\%.

Synthesis of mesoporous carbon materials templated by $P H E A_{25}-b-P S_{118}$ copolymer nanoparticles (run a). In a typical procedure, phloroglucinol (0.205 g, $1.63 \mathrm{mmol})$ and glyoxylic acid monohydrate $(0.152 \mathrm{~g}, 2.05 \mathrm{mmol})$ were dissolved under stirring at room temperature in methanol (1.96 g). This solution was then added to a non-purified $\mathrm{PHEA}_{25}-b-\mathrm{PS}_{118}$ copolymer dispersion (4.96 g). This leads to a molar ratio phloroglucinol:glyoxylic acid:template = 1:1:0.020. Methanol $(0.723 \mathrm{~g})$ was added to the reaction mixture to obtain a total weight of $8 \mathrm{~g}$, which was also kept constant in all runs. The turbid sample was transferred into smooth glass dishes and left at room temperature for $6 \mathrm{~h}$ in order to evaporate methanol solution and the nonreacted styrene. Subsequently, a thermal consolidation of the phenolic resin was performed at 60 ${ }^{\circ} \mathrm{C}$ overnight to increase the cross-linking density of the phenolic resin framework. The resultant 
material was pyrolysed at $600{ }^{\circ} \mathrm{C}$ under argon for $2 \mathrm{~h}$. In the series of experiments involving a variation of template concentrations (run $e-h$ ), the molar ratio $r=\mathrm{n}$ (copolymer) $/ \mathrm{n}($ copolymer) run a was changed from 1 to 0.2 . In these cases, the molar ratio phloroglucinol:glyoxylic acid:template $=$ $1: 1: 0.020 \times r$.

Synthesis of PS nanolatex. PS latex was prepared using semi-continuous emulsion polymerization. In this method, surfactant (SDS, $0.2024 \mathrm{~g}, 0.701 \mathrm{mmol}$ ) and initiator (ammonium persulfate, $0.0264 \mathrm{~g}, 0.116 \mathrm{mmol}$ ) were dissolved in water (40 g) and added to a glass reactor (Schlenk tube) equipped with a stainless steel stirrer, a reflux condenser, a sampling device, a nitrogen gas inlet tube, and a temperature probe. When the reaction temperature was reached $\left(80^{\circ} \mathrm{C}\right)$, the monomer $(8.8 \mathrm{~g}, 84.5 \mathrm{mmol})$ was continuously fed $\left(49 \mathrm{mg} \mathrm{min}^{-1}\right)$ over a period of $3 \mathrm{~h}$. At the end of monomer feeding, the system was maintained at the reaction temperature for $60 \mathrm{~min}$ in order to minimize the amount of residual monomer.

\section{CHARACTERIZATIONS}

Nuclear magnetic resonance (NMR). ${ }^{1} \mathrm{H}$ spectra were recorded in $\mathrm{D}_{2} \mathrm{O}$ (homopolymers) or $\mathrm{CDCl}_{3}$ (diblock copolymer and PS latex) at $300 \mathrm{MHz}$ on a Varian Mercury spectrometer.

Transmission electron microscopy (TEM). The TEM images of copolymer nanoparticles (templates), PS latex, phenolic resin/templates and carbon mesoporous materials were obtained with a JEOL ARM-200F instrument working at $200 \mathrm{kV}$. Copolymer based templates and PS latex samples were diluted 20 times, cast onto the TEM grid, and dried overnight at room temperature. For TEM tomography, a series of 1000 images was acquired between $-60^{\circ}$ and $+60^{\circ}$ every $1^{\circ}$. Image alignments and reconstructions were performed using the TEMography software. 
Scanning electron microscopy (SEM). High resolution images were obtained using a JEOL JSM-7900F field emission SEM working with a $5 \mathrm{kV}$ stage bias voltage and a low accelerating voltage of $1 \mathrm{kV}$. The samples were observed without any preparation.

Size exclusion chromatography (SEC). Molecular weights of PHEA-b-PS copolymers were determined by SEC in DMF with additive of $0.01 \mathrm{M} \mathrm{LiBr}$ at $50{ }^{\circ} \mathrm{C}$. For sample preparation, an aliquot was precipitated in $2 \mathrm{~mL}$ of diethyl ether under intense stirring, then the copolymer collected after filtration was dried and dissolved in DMF. Solutions of samples with precise concentrations around 1-3 $\mathrm{mg} \mathrm{mL}^{-1}$ were then prepared and filtered (PTFE membrane; $0.20 \mu \mathrm{m}$ ) before injection. The flow rate was $0.9 \mathrm{~mL} \mathrm{~min}^{-1}$. The following Agilent 1260 Infinity series setup was used: a G1311A isocratic pump; a G1322A degasser; a G1313A auto-sampler; a G1316A thermostated column compartment equipped with a set of Polymer Laboratories ResiPore columns (nominal particle size: $3 \mu \mathrm{m}$; porosity: $2 \mu \mathrm{m}$ ) composed of a guard column (50 $\times 7.5 \mathrm{~mm})$ and two columns $(300 \times 7.5 \mathrm{~mm})$; a G1314B variable wavelength detector; a G7800A multidetector suite equipped with a MDS refractive index detector. Relative calibration was performed using a set of EasiVial poly(methyl methacrylate) (PM) standards. Agilent GPC/SEC software and multi-detector upgrade were used to determine molar mass values and distributions.

Differential Scanning Calorimetry (DSC). A Mettler Toledo DSC1 was used for thermal analysis and glass transition temperature determination. The macro-CTA and copolymer samples were heated from -50 to $150{ }^{\circ} \mathrm{C}$, cooled to $-50{ }^{\circ} \mathrm{C}$ and re-heated to $150{ }^{\circ} \mathrm{C}$. The heating and cooling rates were $+/-10{ }^{\circ} \mathrm{C} / \mathrm{min}$. Glass transition temperatures was determined during the $3^{\text {rd }}$ heating cycle. 
Thermo-gravimetric analysis (TGA). was used to study the mass loss during phenolic resin/template thermal treatment by heating with $2{ }^{\circ} \mathrm{C} \min ^{-1}$ up to $600{ }^{\circ} \mathrm{C}$ under nitrogen (Mettler-Toledo TGA 851e).

Nitrogen sorption analysis. The textural properties of the materials were investigated with a Micromeritics ASAP 2020 instrument using $\mathrm{N}_{2}$ adsorbate at $-196{ }^{\circ} \mathrm{C}$. Prior to the analysis, the samples were out-gassed overnight in a vacuum at $300{ }^{\circ} \mathrm{C}$ on the degassing port followed by $4 \mathrm{~h}$ out-gassing on the analysis port. The BET (Brunauer-Emmett-Teller) surface area $\left(S_{\mathrm{BET}}\right)$ was calculated from the linear plot in the relative pressure range of $0.05-0.3$ while the micropore volume ( $\left.V_{\text {micro }}\right)$ was determined using the Dubinin-Radushkevich (DR) equation. The mesopore

volume $\left(V_{\text {meso }}\right)$ was obtained by subtracting the micropore volume from the total pore volume of $\mathrm{N}_{2}$ adsorbed at a relative pressure $P / P_{0}$ of 0.95 (in some particular cases 0.99 ). The average mesopore size was determined with the BJH (Barrett-Joyner-Halenda) model on the adsorption branch. The micropore size distribution was determined using the $\mathrm{N}_{2}$ non-local density functional theory (NLDFT) model for slit pores.

\section{RESULTS AND DISCUSSION}

\section{SYNTHESIS AND CHARACTERIZATION OF CORE-SHELL NANOPARTICLE}

\section{TEMPLATE}

We used reversible addition-fragmentation chain-transfer (RAFT) polymerization, a wellestablished controlled radical polymerization method to mediate the PISA process and produce the PHEA- $b$-PS core-shell nanoparticles. Thoroughly described in a previous publication, ${ }^{28}$ the synthesis procedure consists in two separates steps: a PHEA block was first synthesized in 
solution (1,4-dioxane), then subjected to a chain-extension with styrene in a mixture of methanol/water $(95 / 5 \mathrm{wt} / \mathrm{wt} \%)$ in which PS is insoluble. This results in a spontaneous selfassembly of PHEA- $b$-PS chains after PS block reaches a critical DP. In the DSC thermograms (see Fig. S1 in SI), the occurrence of two $T_{g} \mathrm{~s}$ in the diblock copolymer system demonstrates that the hydrophilic and hydrophobic blocks selected are thermodynamically incompatible and form different domains. This is supposed to drive nanophase separation in dispersion, and consequently, the formation of particles endowed with core-shell morphology. Another advantage of a RAFT mechanism is the precise and independent control of DP for the two blocks as shown by size exclusion chromatrography (SEC) traces displaying narrow dispersities (see examples in Fig. S2, SI). The PISA syntheses were all conducted at $20 \mathrm{wt} \%$ solids content allowing to comply with request of high latex concentration for the subsequent carbon templated synthesis.

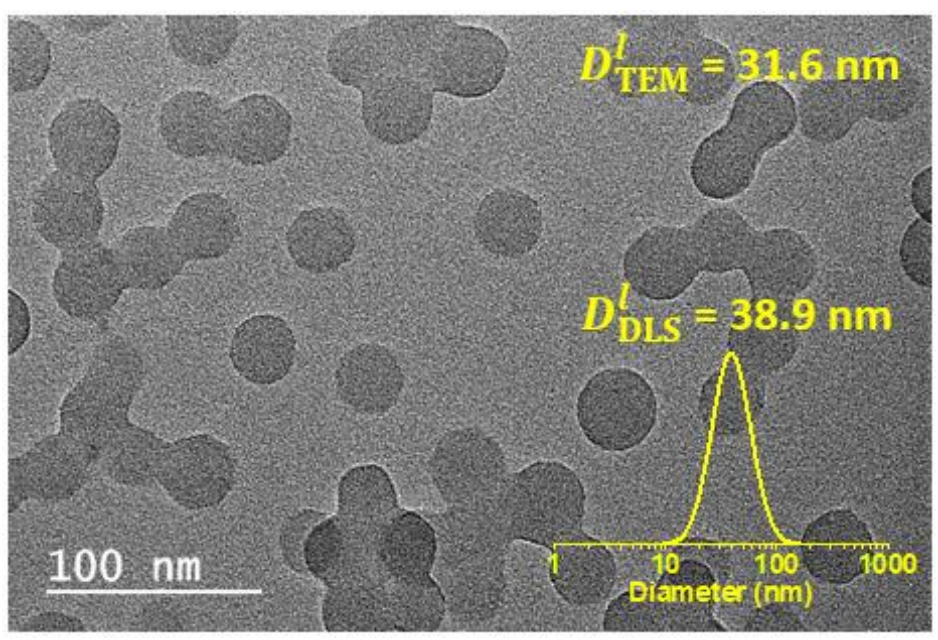

Figure 2. TEM image of $\mathrm{PHEA}_{25}-b-\mathrm{PS}_{118}$ copolymer nanoparticles prepared in methanol: $\mathrm{H}_{2} \mathrm{O}$ mixture $(95: 5 \mathrm{wt} / \mathrm{wt} \%)$ solution. The inset shows the number size distribution obtained from DLS data.

Figure 2 shows a representative TEM picture obtained from $\mathrm{PHEA}_{25}-b-\mathrm{PS}_{118}$ latex $\left(M_{\mathrm{n}}(\mathrm{PHEA})=2900 \mathrm{~g} \mathrm{~mol}^{-1}\right.$ and $\left.M_{\mathrm{n}}(\mathrm{PS})=12300 \mathrm{~g} \mathrm{~mol}^{-1}\right)$. The spherical particles exhibit a 
narrow particle size dispersity $\left(P D I_{\mathrm{TEM}}^{l}=1.05\right)$ and a small apparent diameter $\left(D_{\mathrm{TEM}}^{l}=31.6 \mathrm{~nm}\right)$. As a result of its sub-ambient $T_{\mathrm{g}}\left(4^{\circ} \mathrm{C}\right)$, the PHEA shell is likely to be melted down by the electron beam. Our assumption is that it may form a transparent thin film surrounding the PS core that is not visible because of a too weak contrast. Therefore, only the PS core possessing a much higher $T_{\mathrm{g}}\left(90{ }^{\circ} \mathrm{C}\right.$, Fig. S1) can be detected by TEM due to its higher stability under the electron beam. To support this assumption, no domain formation can be seen in the inner core area, and a sharp interface is clearly visible. The collapse of the PHEA shell impedes the use of TEM for particle sizing, but provides a useful insight into the PS core's dimension, which eventually determines the size of the future mesopore in the carbon materials. Therefore, only indirect methods such as light scattering measurements (DLS) can give information on full particle size and size distribution. As can be seen in the inset of Figure 2, the DLS distribution reveals a small polydispersity $\left(P D I_{\mathrm{DLS}}^{l}=0.174\right)$ and a higher average diameter of $D_{\mathrm{DLS}}^{l}=38.9$ nm. Taking into account the soft poly(acrylate) shell, the DLS-derived value is consistently higher, and provides a rough estimation of the solvated shell $(\delta=5-10 \mathrm{~nm})$ by taking the difference between DLS and TEM particle diameters $\left(\delta=D_{\mathrm{DLS}}^{l}-D_{\mathrm{TEM}}^{l}\right)$. Furthermore, the latex shows a high colloidal stability over time, and no significant variation of particle diameter is observed by TEM over a period of 12 months $\left(\Delta D_{\mathrm{TEM}}^{l}=+1.9 \mathrm{~nm}\right)$ (Fig. S3 in SI). The efficiency of steric stabilization is also reflected by the ability to re-disperse the nanoparticles in water through dialysis without significant aggregation. Similarly, no sign of destabilization is found when $\mathrm{PHEA}_{25}-b-\mathrm{PS}_{118}$ particles are dispersed in the mixture of phenolic precursors for the preparation of the mesoporous material. As expected from a steric stabilization, the acidic solution containing glyoxylic acid and phloroglucinol precursors did not affect stability. 


\section{MESOPOROUS CARBON THROUGH CORE-SHELL NANOPARTICLE TEMPLATING}

Mesoporous materials were prepared following a conventional templating procedure schematically illustrated in Figure 3. As described above, a colloidally stable dispersion based on $\mathrm{PHEA}_{25}-b-\mathrm{PS}_{118} /$ phenolic resin mixture containing a template content of $60 \mathrm{wt} \%$ with respect to the monomers was aged at room temperature for $6 \mathrm{~h}$. The objective was to ensure slow condensation and removal of most solvent and residual monomer by evaporation. Condensation was then completed at $60{ }^{\circ} \mathrm{C}$ for $12 \mathrm{~h}$. At this stage (i.e. prior to pyrolysis), TEM analysis shows a homogeneous template/phenolic resin composite, where the intimate mixing of the two polymers does not allow for the discrimination of nanoparticles (see Fig. S4, SI). The brown composite residue was further pyrolysed at $600{ }^{\circ} \mathrm{C}$ in argon to decompose the phenolic polymer leading to the carbon network creation and to eliminate the organic polymer nanoparticles in a single step, resulting in the mesopore formation.

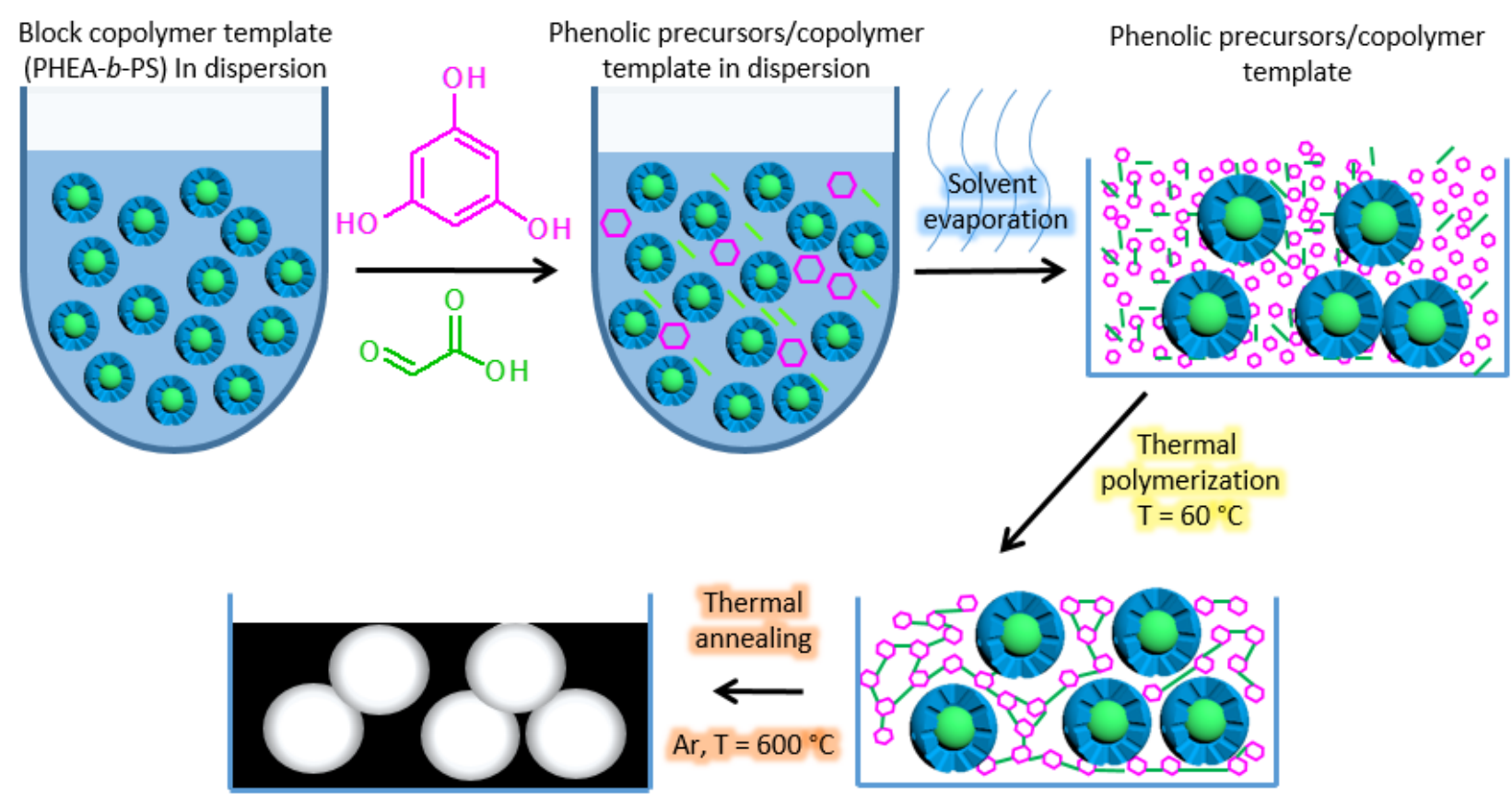

Figure 3. Process for the synthesis of mesoporous carbon using core-shell diblock copolymer nanoparticles 
MORPHOLOGY AND STRUCTURE. Figure 4a-b shows some typical TEM images at different scales of the mesoporous carbon derived from $\mathrm{PHEA}_{25}-b-\mathrm{PS}_{118}$ copolymer nanoparticles. The characteristic structure of a mesostructured cellular foam can be recognized, which consists of a disorder array of spherical mesopores framed by the carbon struts. The structure obtained is also reminiscent of carbon aerogels, but in our case, the sample displays a narrower size distribution of pores $\left(D_{\text {TEM }}^{\mathrm{p}}=21-23 \mathrm{~nm}\right)$, reflecting the limited dispersity in size of the particle templates $\left(D_{\text {TEM }}^{l}=29-33 \mathrm{~nm}\right)$. The random distribution of pores was also verified by X-ray scattering. Such result is explained by the non-perfect packing of the spherical colloidal particles as result of their slight polydispersity. This contrasts with a conventional colloidal crystal templating approach resulting in ordered macroporous materials. ${ }^{2}$ An average pore size $\left(D_{\text {TEM }}^{\mathrm{p}}\right)$ of $22 \mathrm{~nm}$ was determined from TEM image, which can be understood on the basis of PS domains' volume contraction $\left(D_{\text {TEM }}^{l}=31.6 \mathrm{~nm}\right)$ after pyrolysis. Therefore, our pore size data lend confidence in a faithful replica of the original template. This mechanism is consistent with the fact that PISA particles are kinetically and mechanically stable templates with less risks to be disrupted in the course of the phenolic resin cross-linking than dynamic structures based on LC mesophases or microemulsions. ${ }^{37}$ The wall thickness $\left(\delta_{\text {TEM }}^{\mathrm{p}}\right)$ of the mesoporous material is estimated to be $\sim 4-5 \mathrm{~nm}$ from TEM pictures, which is relatively significant compared to other materials prepared by particle/emulsion templating. ${ }^{7,14}$ Indeed, when two particles approach each other, steric repulsion between PHEA layers solvated by phenolic precursors limit the overlap, resulting in thick and robust framework walls. However, we were unable to establish from TEM imaging whether the foam structure was made up of interconnected pores due to poor contrast between cells, windows and the carbon framework. In order to reveal in greater details the 3D structure of this sample, electron microscopy tomography was performed. Figure $4 \mathbf{c}$ 
shows a tilt series of five characteristic images where windows connecting the cells are clearly visualized. Pore connectivity in the whole sample is proven from the full tilt series of 1000 images (see movies M1 in SI).
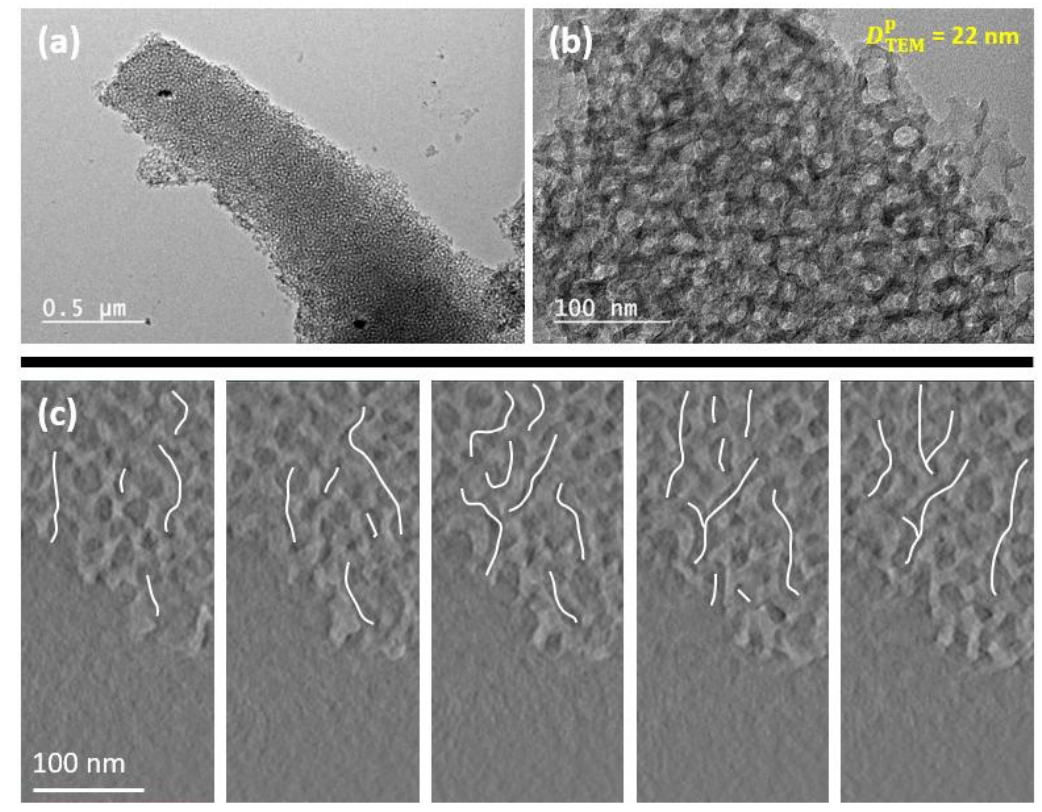

Figure 4. (a) TEM images of mesoporous carbon templated by $\mathrm{PHEA}_{25}-b-\mathrm{PS}_{118}$ copolymer nanoparticles, (b) higher magnification image of the same sample, (c) electron tomography tilt series where interconnected pores are indicated by solid white lines (movie available as supplementary movie M1 in SI).

TEXTURAL PROPERTIES. The porosity of the mesostructured carbon derived from PHEA $_{25}$ $b$ - $\mathrm{PS}_{118}$ template has been also investigated by nitrogen adsorption analysis. Pore volumes $\left(V_{\mathrm{T}}\right.$, $V_{\text {meso }}$ and $\left.V_{\text {micro }}\right)$, pore diameters $\left(D_{\mathrm{BJH}}^{\mathrm{p}}\right)$ and surface areas $\left(S_{\mathrm{BET}}\right)$ for this reference sample (run $\left.a\right)$ are summarized in the first line of Table 1. As shown in Figure 5, its nitrogen adsorption/desorption isotherms exhibits a type IV isotherm according to IUPAC classification, ${ }^{38}$ which is characteristic of mesoporous materials. A steep rise at low relative pressure $\left(P / P_{0}\right)$ is associated with micropore filling $\left(V_{\text {micro }}=0.29 \mathrm{~cm}^{3} \mathrm{~g}^{-1}\right)$. Control experiments without template revealed a material devoid of mesopores, but also microporous. In this case, $V_{\text {micro }}$ ranges 
between 0.15 and $0.20 \mathrm{~cm}^{3} \mathrm{~g}^{-1}$, suggesting that microporosisty in our latex-templated sample results primarily from carbon walls. At higher relative pressures, the isotherm shows a steep hysteresis of $\mathrm{H}_{1}$-type with a characteristic symetrical shape. This feature is indicative of a narrow range of uniform and open mesopores where networking effects are limited. As supported by TEM data, the porous structure is composed of large spherical cells, interconnected by windows or channels that are sufficiently large to prevent pore blocking effects. Consequently, the desorption branch is not delayed, as is the case in networked structures where nitrogen evaporation can be hindered by narrow pore constrictions. ${ }^{39}$ The surface area was evaluated by the Brunaeur-Emmet-Teller (BET) method, and $S_{\mathrm{BET}}$ was estimated to be $691 \mathrm{~m}^{2} \mathrm{~g}^{-1}$ which is similar to carbon templated by surfactant. ${ }^{40}$ Pore size distribution (see inset of Figure 5) based on Barrett-Joyner-Halenda (BJH) model reveals a mesopore distribution ranging from 10 to $30 \mathrm{~nm}$. The average mesopore size of $22 \mathrm{~nm}\left(D_{\mathrm{BJH}}^{\mathrm{p}}\right)$ is fully consistent with TEM results $\left(D_{\mathrm{TEM}}^{\mathrm{p}}=22 \mathrm{~nm}\right)$. The size distribution of micropores determined by NLDFT method shows a small population at $0.5 \mathrm{~nm}$ together with a larger one at $1.4 \mathrm{~nm}$.

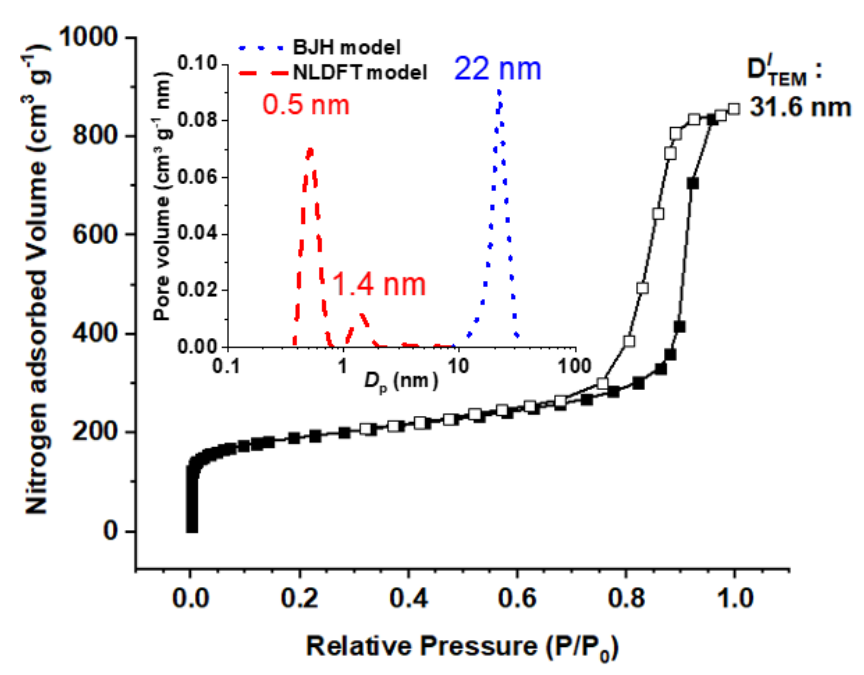

Figure 5. Nitrogen adsorption/desorption isotherms of carbon material template by $\mathrm{PHEA}_{25}-b$ $\mathrm{PS}_{118}$ copolymer nanoparticles. The inset provides the meso- and micropore size distributions obtained from BJH and NLDFT methods, respectively. 
Table 1. Textural and structural properties of carbon materials synthesized using different copolymer template structure and concentration.

\begin{tabular}{|c|c|c|c|c|c|c|c|c|c|}
\hline Template & Run & $r$ & $\begin{array}{l}D_{\text {TEM }}^{l} \\
\mathbf{n m}\end{array}$ & $\begin{array}{r}S_{\mathrm{BET}} \\
\mathbf{m}^{2} \mathbf{g}^{-1}\end{array}$ & $\begin{array}{c}V_{\mathrm{T}} \\
\mathbf{c m}^{3} \mathrm{~g}^{-1}\end{array}$ & $\begin{array}{l}V_{\text {micro }} \\
\mathrm{cm}^{3} \mathrm{~g}^{-1}\end{array}$ & $\begin{array}{r}V_{\text {meso }} \\
\mathrm{cm}^{3} \mathrm{~g}^{-1}\end{array}$ & $\begin{array}{c}D_{\mathrm{BJH}}^{\mathrm{p}} \\
\mathrm{nm}\end{array}$ & $\begin{array}{c}D_{\text {TEM }}^{p} \\
\mathbf{n m}\end{array}$ \\
\hline
\end{tabular}

Effect of PHEA and PS block length

\begin{tabular}{llllllllll}
\hline PHEA $_{25}-\boldsymbol{b}-\mathbf{P S}_{\mathbf{1 1 8}}$ * & $\boldsymbol{a}$ & $\mathbf{1}$ & $\mathbf{3 1 . 6}$ & $\mathbf{6 9 1}$ & $\mathbf{1 . 3 0}$ & $\mathbf{0 . 2 9}$ & $\mathbf{1 . 0 1}$ & $\mathbf{2 2}$ & $\mathbf{2 2}$ \\
PHEA $_{25}-b-\mathrm{PS}_{\mathbf{1 6 0}}$ & $b$ & 1 & 42.1 & 702 & 1.58 & 0.34 & 1.24 & 22 & 29 \\
PHEA $_{\mathbf{5 2}}-b-\mathrm{PS}_{110}$ & $c$ & 1 & 24.0 & 498 & 0.41 & 0.19 & 0.22 & 25 & 19 \\
PHEA $_{\mathbf{8 5}}-b-\mathrm{PS}_{114}$ & $d$ & 1 & 20.5 & 369 & 0.28 & 0.14 & 0.14 & 22 & 16 \\
\hline
\end{tabular}

\begin{tabular}{lccccccccc}
\hline \multicolumn{10}{l}{ Variation of template concentration } \\
\hline PHEA $_{28}-b-\mathrm{PS}_{134}$ & $e$ & $\mathbf{0 . 8}$ & 32.1 & 714 & 1.25 & 0.31 & 0.94 & 22 & 20 \\
PHEA $_{28}-b-\mathrm{PS}_{134}$ & $f$ & $\mathbf{0 . 6}$ & 32.1 & 717 & 1.14 & 0.31 & 0.83 & 22 & 22 \\
PHEA $_{28}-b-\mathrm{PS}_{134}$ & $g$ & $\mathbf{0 . 4}$ & 32.1 & 687 & 1.02 & 0.29 & 0.73 & 22 & 23 \\
PHEA $_{28}-b-\mathrm{PS}_{134}$ & $h$ & $\mathbf{0 . 2}$ & 32.1 & 640 & 0.73 & 0.26 & 0.47 & 22 & 23 \\
\hline
\end{tabular}

$r=\frac{\mathrm{n}(\text { copolymer })}{\mathrm{n} \text { (copolymer })_{\text {run }}} . D_{\text {TEM }}^{l}-$ Average diameter of latex nanoparticles (TEM data). $S_{\mathrm{BET}}-$ BET surface area determined by the BET method. $V_{\mathrm{T}}, V_{\text {micro }}$ and $V_{\text {meso }}-$ Total pore volume, micropore volume and mesopore volume, respectively. $D_{\mathrm{BJH}}^{\mathrm{p}}-\mathrm{Mesopore}$ diameter calculated by the BJH method from the isotherm adsorption branch. $D_{\mathrm{TEM}}^{p}-$ Mesopore diameter (TEM data).

THERMAL PROPERTIES. The hybrid nanoparticle/phenolic resin solid was also subjected to thermogravimetric analysis under nitrogen in order to shed light into the template decomposition and the conversion of phenolic resin into carbon material. As shown in Figure 6, the total weight loss of pyrolyzed carbon is $80 \%$. The TGA thermogram shows two distinct and separate weightloss steps: a gradual and limited weight loss $(\sim 10 \%)$ between 50 and $300{ }^{\circ} \mathrm{C}$ due to water desorption and degradation of short polymer chains, and a much more significant weight-loss $(\sim 70 \%)$ in the temperature range $350-420{ }^{\circ} \mathrm{C}$. This second weight change transition is highlighted by plotting the corresponding derivative on the right side y-axis. This results in a well-defined and intense peak centered at $405{ }^{\circ} \mathrm{C}$, assigned to the simultaneous decomposition of $\mathrm{PHEA}_{25}-b-\mathrm{PS}_{118}$ copolymer and phenolic resin. A control experiment where PHEA $25-b-\mathrm{PS}_{118}$ was analyzed individually corroborates this conclusion, and also leads to a complete weight loss. 
This latter result illustrates that none of the polymer blocks serves as carbon precursor, and both are sacrificed upon pyrolysis. ${ }^{41}$ We believe that the high thermal stability for copolymer particles is key to the success of our latex templating approach. By delaying the elimination of the template, further polycondensation reactions between phloroglucinol and glyoxylic acid can take place in a way that template's shape and morphology can be efficiently imprinted. As a result, the material is able to withstand drying and carbonization without collapse of the mesostructure.

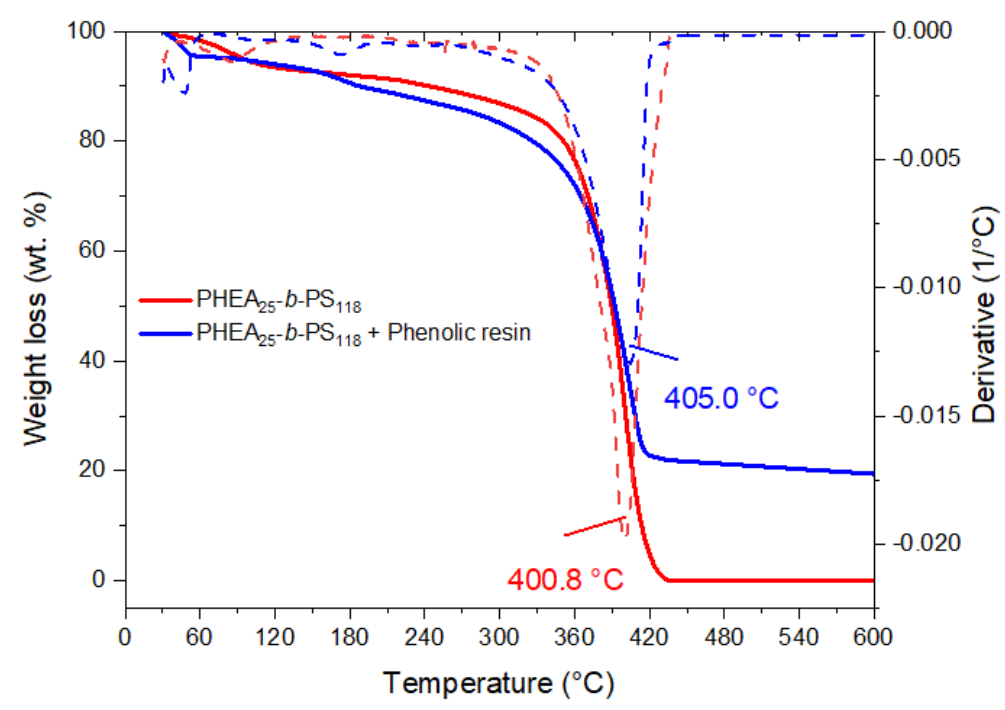

Figure 6. Thermogravimetric plots showing the variation of weight loss (solid line) and its derivative (dashed line) of $\mathrm{PHEA}_{25}-b-\mathrm{PS}_{118}$ copolymer nanoparticles and the composite $\mathrm{PHEA}_{25}$ $b$ - $\mathrm{PS}_{118}$ nanoparticle/phenolic resin.

\section{EFFECT OF VARIOUS EXPERIMENTAL PARAMETERS}

EFFECT OF PHEA AND PS BLOCKS LENGTH. An advantage resulting from the controlled radical polymerization process is the precise and independent tuning of solvophobic and solvophilic block's DP. Using PHEA $_{25}-b-\mathrm{PS}_{118}$ block copolymer as reference (run $a$, Table 1), three other diblock copolymers templates were employed for the nanoporous carbon synthesis: PHEA $_{25}-b-\mathrm{PS}_{160}$ (run $b$ ) to assess the influence of the length of the solvophobic block; PHEA $2_{52^{-}}$ $b$ - $\mathrm{PS}_{110}$ (run $c$ ) and $\mathrm{PHEA}_{85}-b-\mathrm{PS}_{114}$ (run $d$ ) to clarify the effect of the solvophilic block. In all 
cases, the dispersity of the copolymer chains was estimated to be 1.2-1.3, and spherical particles with a narrow size distribution were achieved (Fig. S5, SI). As summarized in Table 1, the general trend of DLS data is that increasing the PS block for $\mathrm{PHEA}_{25}-b-\mathrm{PS}_{160}$ causes the formation of larger particles: $D_{\mathrm{DLS}}^{l}=45.0 \mathrm{~nm}$ versus $38.9 \mathrm{~nm}$ for $\mathrm{PHEA}_{25}-b$-PS 118 . PHEA chain length being unchanged, PS growth causes an increase of particle surface area, which can be only accommodated by the incorporation of new copolymer chains to stabilize the particles, resulting in a particle size increase. Conversely, the stronger steric stabilization of $\mathrm{PHEA}_{52}-b$ $\mathrm{PS}_{110}$ and $\mathrm{PHEA}_{85}-b-\mathrm{PS}_{114}$ yields smaller particles, $D_{\mathrm{DLS}}^{l}=30.1$ and $33.2 \mathrm{~nm}$ respectively. As expected, the TEM size data (see $D_{\text {TEM }}^{l}$ in Table 1) show a similar range of variations. However, smaller values are obtained because only the PS core can be imaged by this technique as previously underscored. Figure 7 shows a series of nitrogen adsorption/desorption isotherms for all these carbon materials (left) together with the corresponding TEM images (right). Like reference sample $a$, TEM imaging shows that all carbon materials possess a disordered mesoporous structure with uniform pores. However, clear differences are noticeable as regards cell size, shape and pore interconnectivity.
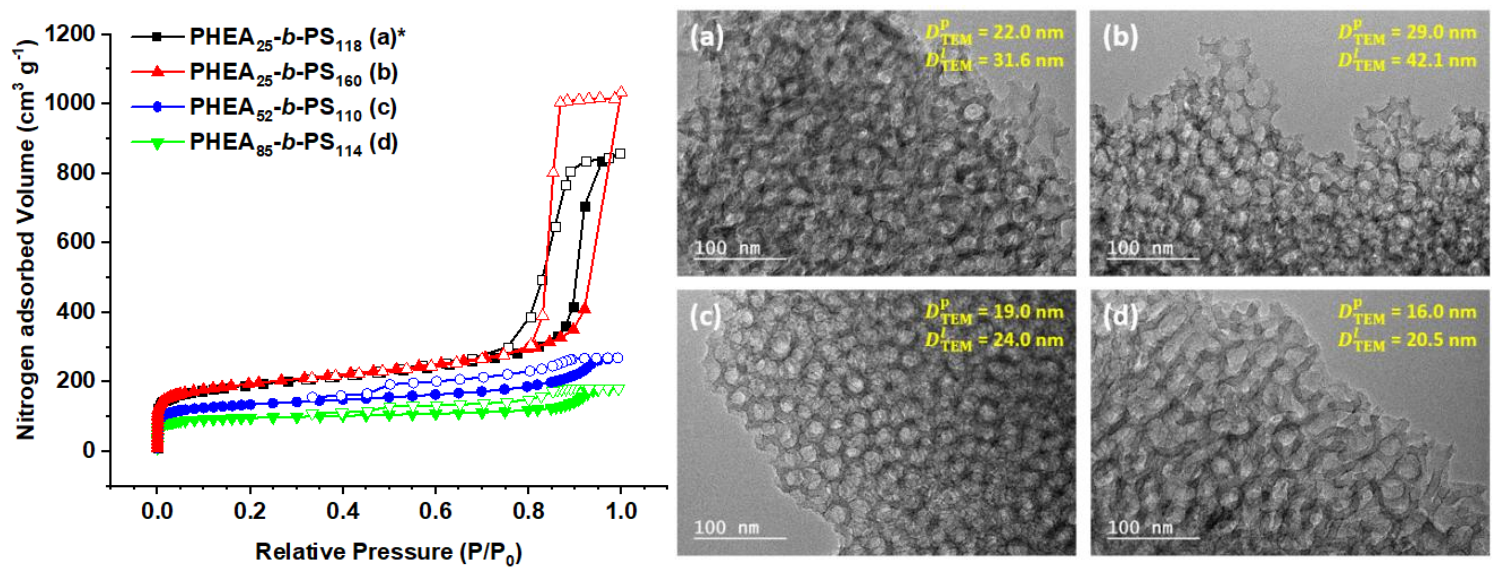

Figure 7. Left: Nitrogen adsorption/desorption isotherms of carbon materials templated by PHEA $_{25}-b-\mathrm{PS}_{118}(a), \mathrm{PHEA}_{25}-b-\mathrm{PS}_{160}(b), \mathrm{PHEA}_{52}-b-\mathrm{PS}_{110}(c)$ and $\mathrm{PHEA}_{85}-b-\mathrm{PS}_{114}(d)$. Right: TEM images of the corresponding materials $\left(D_{\text {TEM }}^{\mathrm{p}}\right.$ is the average pore size). In this series, a steady molar ratio phloroglucinol:glyoxylic acid:template $=1: 1: 0.020$ was chosen. 
Using $\mathrm{PHEA}_{25}-b-\mathrm{PS}_{160}(b)$ instead of $\mathrm{PHEA}_{25}-b-\mathrm{PS}_{118}(a)$, the carbon pore size $D_{\mathrm{TEM}}^{p}$ increases from $22.0 \mathrm{~nm}$ to $29.0 \mathrm{~nm}$, which is consistent with the larger PS core in the initial latex $\left(D_{\text {TEM }}^{l}=\right.$ $42.1 \mathrm{~nm}$ vs $31.6 \mathrm{~nm}$ ). This supports PS core dimension as a key parameter controlling mesopore size. Like carbon $a$, the sample $b$ templated by $\mathrm{PHEA}_{25}-b-\mathrm{PS}_{160}$ copolymer exhibits also a type IV isotherm characteristic of mesoporous materials. As expected, changing the PS length does not change the BET surface area $\left(S_{\mathrm{BET}}=702 \mathrm{~m}^{2} \mathrm{~g}^{-1}\right)$ and micropore volume $\left(V_{\text {micro }}=0.34 \mathrm{~cm}^{3}\right.$ $\left.\mathrm{g}^{-1}\right)$. Additionally, the total pore volume is higher for the $\operatorname{PHEA}_{25}-b-\mathrm{PS}_{160}\left(1.58 \mathrm{~cm}^{3} \mathrm{~g}^{-1}\right)$ compared to $\mathrm{PHEA}_{25}-b-\mathrm{PS}_{118}$ material $\left(1.3 \mathrm{~cm}^{3} \mathrm{~g}^{-1}\right)$ due to a larger diameter of pores induced by the larger template size and higher mesopore volume. In contrast to the reference system $a$ exhibiting a $\mathrm{H}_{1}$-type hysteresis, a typical $\mathrm{H}_{2}$-type hysteresis is found with a broader and almost flat saturation plateau at high $\mathrm{P} / \mathrm{P}^{\circ}$. This reflects a delayed desorption step of the gas molecules due to some pore confinement. A similar quantity of copolymer was added in the two samples, but larger size of $\mathrm{PHEA}_{25}-b-\mathrm{PS}_{160}$ latex leads to a lower density of particles in $b$ compared to $a$ (approximately 2 times lower), thus creating a greater interparticle distance. Compared to $\mathrm{PHEA}_{25}-b-\mathrm{PS}_{118}$, the structure is thus moving from an array of interconnected pores in $a$ to an assembly of cavities connected by much narrower constrictions in $b$. Consequently, the spherical shape of the pores is less distorted and appear more resolved in the TEM picture. In such pore blocking model found in carbon $b$, pore emptying is delayed and proceeds presumably through a percolation process which accounts for the asymmetrical shape of hysteresis loop. In $\mathrm{H}_{2}$-type hysteresis, a precise pore size distribution is generally difficult to obtain, ${ }^{42-44}$ and accordingly, the average mesopore size $\left(D_{\mathrm{BJH}}^{\mathrm{p}}=22 \mathrm{~nm}\right.$, Table 1$)$ is significantly underestimated compared to TEM data $\left(D_{\mathrm{TEM}}^{\mathrm{p}}=29 \mathrm{~nm}\right)$. 
For the two other carbons prepared with the latex exhibiting a longer PHEA stabilizing block and similar PS block (run $c$ and $d$ ), smaller pores $\left(D_{\mathrm{TEM}}^{\mathrm{p}}=16-19 \mathrm{~nm}\right)$ are found compared to carbon $a$ in accordance with the decreased size of the PS core $\left(D_{\text {TEM }}^{l}=20-24 \mathrm{~nm}\right)$. In addition, these two samples seem characterized in the TEM images by a higher extent of closed porosity with more isolated and not connected mesopores. As a result, the pores possess a welldefined spherical shape, and a much thicker wall separates neighboring pores: $\delta_{\mathrm{TEM}}^{\mathrm{p}} \sim 7-8 \mathrm{~nm}$ in carbon $c\left(\mathrm{PHEA}_{52}-b-\mathrm{PS}_{110}\right)$ and $9-10 \mathrm{~nm}$ in carbon $d\left(\mathrm{PHEA}_{85}-b-\mathrm{PS}_{114}\right)$. This structure is in contrast to the carbon $a$ derived from $\mathrm{PHEA}_{25}-b-\mathrm{PS}_{118}$ that gives rise to an open porosity manifested by a highly interconnected mesoporous structure. Consequently, a much lower density of pores is thus generated, leading to a 5 -fold decrease of the mesopore volume $\left(V_{\text {meso }}=\right.$ $\left.0.1-0.2 \mathrm{~cm}^{3} \mathrm{~g}^{-1}\right)$ as determined from the adsorption isotherms. A type H5 loop can be also recognized in Figure 7, which is reminiscent of complex and heterogeneous porous structures containing both open and partially blocked mesopores. ${ }^{45}$ To provide a definitive answer on the effect of the solvophilic shell on pore architecture and interconnectivity, scanning electron microscopy (SEM) was used because of its topographic contrast imaging capacity. The SEM images in Figure 8 highlight most clearly the contrast between the highly interconnected structure of carbon $a\left(\mathrm{PHEA}_{25}-b-\mathrm{PS}_{118}\right)$ and the closed porosity of carbon $d\left(\mathrm{PHEA}_{85}-b-\mathrm{PS}_{114}\right)$, which agrees closely with both TEM and adsorption data. 

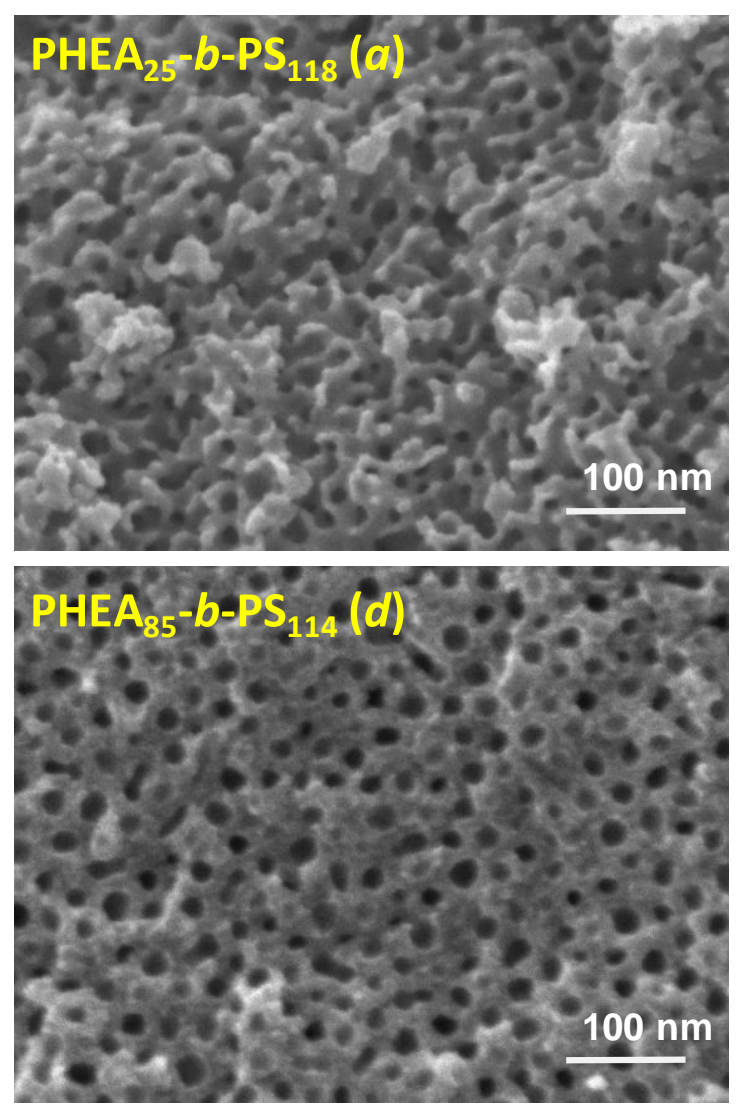

Figure 8. SEM images of carbons $a$ and $d$ templated respectively by $\mathrm{PHEA}_{25}-b-\mathrm{PS}_{118}$ and PHEA $_{85}-b-\mathrm{PS}_{114}$ diblock copolymers

We therefore conclude that wall thickness can be adjusted by the spatial extent of the stabilizing layer (particle shell). Steric stabilization results from solvated PHEA chains anchored on the particle surface, which hinders the approach of other particles and thus acts as a mechanical barrier to flocculation or coalescence. The steric barrier surrounding the particle will be extended upon increasing the DP of PHEA. Because the stabilizing shell is highly solvated by the phenolic resin, it results in a broadening of carbon wall surrounding the pores after carbonization. In agreement with this reasoning, a system of densely packed copolymer particles under TEM show that the average distance separating two PS cores (pore precursor) tends to increase with PHEA length (Fig. S6, SI). As a last comment, a significant drop of microporous 
volume is also noted: $V_{\text {micro }}=0.1-0.19 \mathrm{~cm}^{3} \mathrm{~g}^{-1}$ versus $0.34 \mathrm{~cm}^{3} \mathrm{~g}^{-1}$ for the reference sample $a$ templated by $\mathrm{PHEA}_{25}-b-\mathrm{PS}_{118}$ and $0.19 \mathrm{~cm}^{3} \mathrm{~g}^{-1}$ for a template-free carbon. This result could be explained by a change of the environment of phenolic resin upon increasing the PHEA shell. In samples $c$ and $d$, a higher fraction of phenolic network is in close contact with PHEA which affects its chains conformation and seems to hinder the process of micropore formation. To understand this result, PHEA homopolymers with differents lenghts were employed as template. However, no decrease of microporosity was observed compared to a template-free sample (see Table S1 and Fig. S7 in SI), which therefore means that a more complex mechanism is likely to proceed with a combined effect of the two copolymer blocks on the microporous domain.

EFFECT OF TEMPLATE CONCENTRATION. In a new series of experiments depicted in Figure 8, the molar ratio $r$ of copolymer $\left(\mathrm{PHEA}_{25}-b-\mathrm{PS}_{118}\right)$ in the experiment to the copolymer used in experiment $a$ was varied: $1(a), 0.8(e), 0.6(f), 0.4(g)$ and $0.2(h)$. Similar pore average diameters (Table 1) and pore size distributions (Fig. S8, SI) were obtained in all instances, consistently with the fact that the same latex was systematically employed. The samples exhibit larger wall thickness $\delta_{\text {TEM }}^{\mathrm{p}}$ upon decreasing template concentration, for example 5-6 nm in carbon $g$ and 6-7 nm in carbon $h$. For $r \leq 0.4(g$ and $h)$, the pores are more widely spaced due to the combined effect of short stabilizing chain $\left(\mathrm{PHEA}_{25}\right)$ and lower particle concentration. Consequently, both wall and pore shapes become clearly distinguishable in the TEM photos. One can draw an analogy with the mesoporous carbons $c$ and $d$ prepared with longer solvophilic block $\left(\right.$ PHEA $_{52}$ and PHEA $_{85}$ ), and where steric stabilization acts also as spacer between PS cores further converted into mesopores (Figure 7). For $r \geq 0.6$ ( $a, e$ and $f$ ), the close packing of spheres results in a dense arrangement where the particles come into close contact. Larger contact area between touching spheres leads to an open porosity with interconnected pores distorting the cell 
spherical shape. This shift of pore topology depending on template concentration is clearly reflected in the adsorption isotherms shown in Figure 9. As $r$ decreases, a gradual broadening of the hysteresis loop is observed with a clear transition from a H1 loop (for $r \geq 0.6$ ) to a H2 loop for $r \leq 0.4$. This change translates the shift from a narrow distribution of interconnected mesopores to a more complex pore network with narrow pore openings. The plateau region of hysteresis loop gradually lowers due to the decrease of mesopore volume: $1.01 \mathrm{~cm}^{3} \mathrm{~g}^{-1}(r=1)$ to $0.47 \mathrm{~cm}^{3} \mathrm{~g}^{-1}(r=0.2)$. This decrease directly results for the lower density of particles in the material. Nevertheless, the BET surface areas is almost unchanged $\left(640-714 \mathrm{~m}^{2} \mathrm{~g}^{-1}\right)$ because the micropore volume remains similar regardless of template content. This series of experiment demonstrates that wall thickness can be independently varied to pore size by varying the latex content.
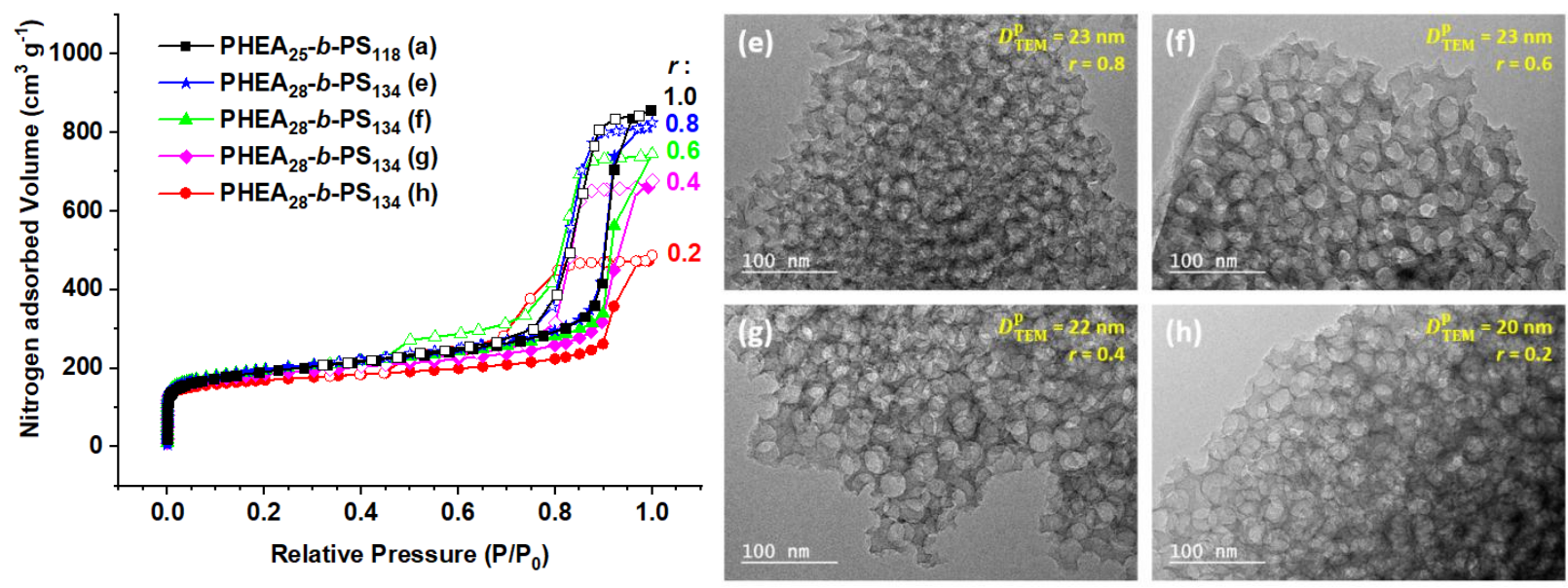

Figure 9. Effect of $\mathrm{PHEA}_{28}-b$ - $\mathrm{PS}_{134}$ template concentration on textural properties of mesoporous carbons. $r$ is the molar ratio of copolymer compared to reference experiment: $r=1(a), 0.8(e)$, $0.6(f), 0.4(g)$ and $0.2(h)$. Left: nitrogen adsorption/desorption isotherms. Right: TEM pictures of corresponding mesoporous carbon materials.

\section{COMPARISON WITH PS AND SILICA COLLOIDAL TEMPLATE}

Table 2. Textural and structural properties of carbon materials synthesized using different templates. 


\begin{tabular}{|c|c|c|c|c|c|c|c|c|}
\hline Template & Run & $\begin{array}{c}D_{\text {TEM }}^{l} \\
\mathbf{n m}\end{array}$ & $\begin{array}{r}S_{\mathrm{BET}} \\
\mathbf{m}^{2} \mathbf{g}^{-1}\end{array}$ & $\begin{array}{c}V_{\mathrm{T}} \\
\mathbf{c m}^{3} \mathbf{g}^{-1}\end{array}$ & $\begin{array}{l}V_{\text {micro }} \\
\mathrm{cm}^{3} \mathrm{~g}^{-1}\end{array}$ & $\begin{array}{c}V_{\text {meso }} \\
\mathrm{cm}^{3} \mathrm{~g}^{-1}\end{array}$ & $\begin{array}{l}D_{\mathrm{BJH}}^{\mathrm{p}} \\
\mathrm{nm}\end{array}$ & $\begin{array}{l}D_{\text {TEM }}^{p} \\
\mathbf{n m}\end{array}$ \\
\hline $\begin{array}{l}\text { PHEA }_{25}-b-P_{118} \\
\text { (sphere) }\end{array}$ & $a$ & 31.6 & 691 & 1.30 & 0.29 & 1.01 & 22 & 22 \\
\hline PS latex & $i$ & 47 & 594 & 2.90 & 0.28 & 2.60 & 40 & 38 \\
\hline Silica particles & $j$ & 23 & 952 & 1.94 & 0.38 & 1.56 & 23 & 20 \\
\hline $\begin{array}{l}\text { PHEA }_{17}-b-\mathrm{PS}_{136} \\
\text { (vesicle) }\end{array}$ & $k$ & $30-170$ & 683 & 1.02 & 0.28 & 0.74 & 28 & - \\
\hline
\end{tabular}

To emphasize the particularity of core-shell nanoparticle templating, mesoporous carbons were produced from two more conventional particles templates: PS and silica nanoparticles.
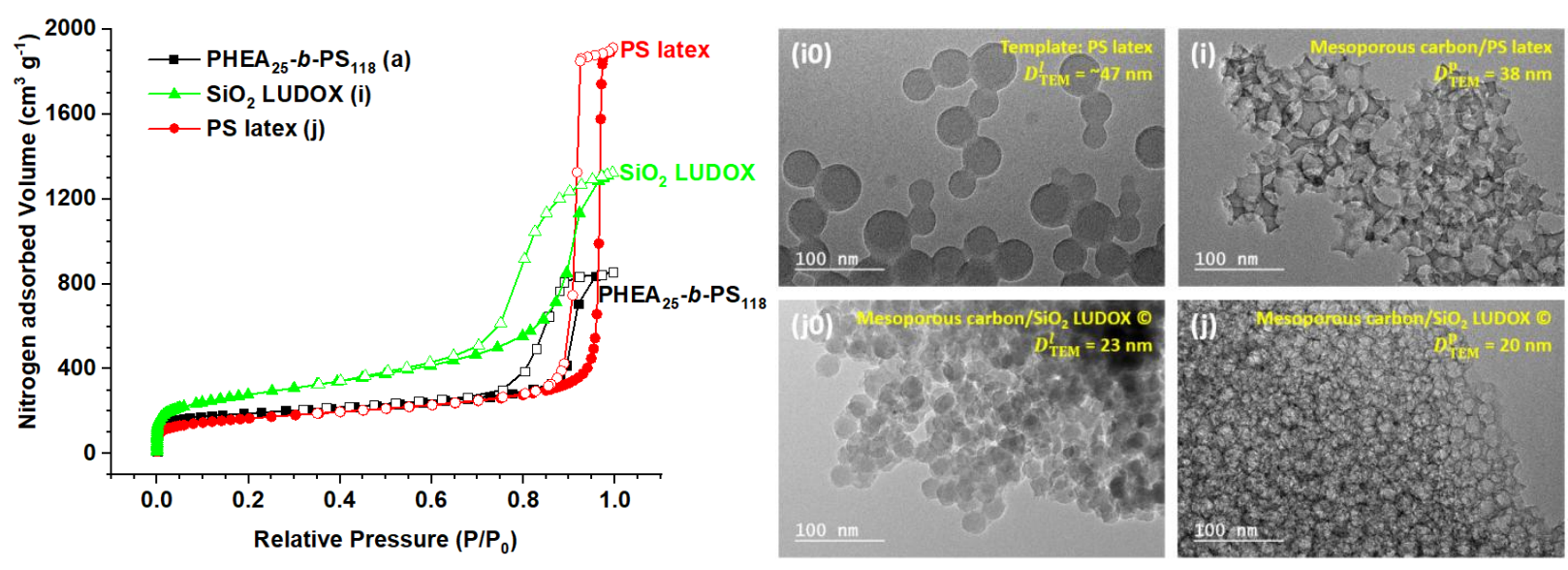

Figure 10. Left: Nitrogen adsorption/desorption isotherms of carbon material templated by PHEA $_{25}-b-\mathrm{PS}_{118}(a)$, PS nanolatex $(i)$ and silica nanoparticle $(j)$. Right: corresponding TEM images of PS latex (iO), mesoporous carbon derived from PS latex $(i)$, phenolic resin $/ \mathrm{SiO}_{2}$ hybrid before $\mathrm{NaOH}$ treatment $(j 0)$, and mesoporous carbon derived from $\mathrm{SiO}_{2}$ nanoparticles $(j)$.

PS LATEX. The PS nanolatex (run $i$, Table 2) stabilized by SDS was prepared following a specific semibatch process ${ }^{13}$ where continuous monomer feeding to a PS seed enables to maitain a small particle size. As expected, TEM imaging (Figure 10, image $i 0$ ) shows particles with an average diameter of $D_{\mathrm{TEM}}^{l}=47 \mathrm{~nm}$ in agreement with DLS measurements $\left(D_{\mathrm{DLS}}^{l}=55 \mathrm{~nm}\right)$. To 
allow a relevant comparison with $\mathrm{PHEA}_{25}-b-\mathrm{PS}_{118}$ latex, a similar weight fraction in polymer template was used for the fabrication of carbon. The main porous properties obtained after carbonization were summarized in Table 2. The most distinctive feature in TEM image of mesoporous carbon (Figure 10, image $i$ ) is pore wall thinning, with the consequence of pore windows occupying a larger area of the surface of the carbon surface. We think that this structure is related to a much thinner SDS stabilizing layer compared to PHEA layer, which favors the building of a sphere-touching network. In addition, its well known that electrostatic stabilization favors a closer packing of particles because repulsion forces are operative at shorter distances compared to steric stabilization. ${ }^{46}$ In contrast to reference sample $a$ templated by copolymer particles, TEM tomography analysis reveal in this case that the structure is only partially interconnected by large windows (Fig. S9 and Movie S2 in SI). As shown in Figure 10, the type IV isotherm exhibits a well-defined and a symmetrical type-H1 hysteresis loop. Compared with carbon $a$, a significantly much larger mesopore volume $\left(V_{\text {meso }}=2.60 \mathrm{~cm}^{3} \mathrm{~g}^{-1}\right)$ was obtained. This result can be understood on the basis of a higher size and density of pores due to thinner walls. In addition, a perfect agreement was observed between the diameter value determined by TEM $\left(D_{\mathrm{TEM}}^{\mathrm{p}}=38 \mathrm{~nm}\right)$ and the one estimated with BJH model $\left(D_{\mathrm{BJH}}^{\mathrm{p}}=40 \mathrm{~nm}\right)$.

COLLOIDAL SILICA. Commercially available silica nanoparticles $\left(D_{\text {TEM }}^{l}=23 \mathrm{~nm}\right)$ was selected as another conventional template to produce mesoporous carbon material. It is worth noting that silica nanoparticles is a hard template which cannot be eliminated during the calcination stage in contrast to polymer particles. Silica template was thus selectively removed after carbonization through washing with a concentrated soda solution (5 M). The TEM images of mesoporous carbon before after template removal are provided in Figure 10. The hybrid mixture phenolic resin/ $/ \mathrm{SiO}_{2}$ (image $j 0$ ) shows a very small interparticle space caused by high 
$\mathrm{SiO}_{2}$ cohesion properties, which make resin domains impossible to distinguish even by high resolution TEM. In the mesoporous carbons (image $j$ ), very thin walls separating an array of highly interconnected mesopores are clearly visible consistently with the previous observation. Compared to copolymer template, there is an increase of both micropore $\left(V_{\text {micro }}=0.38 \mathrm{~cm}^{3} \mathrm{~g}^{-1}\right)$ and mesopore $\left(V_{\text {meso }}=1.56 \mathrm{~cm}^{3} \mathrm{~g}^{-1}\right)$ volume. If the first value is related to different interactions between surface groups of silica nanoparticles, the second is the direct consequence of higher dense packing driven by smaller walls. Surface area is $S_{\mathrm{BET}}=952 \mathrm{~m}^{2} \mathrm{~g}^{-1}$ (40\% higher than in reference sample $a$ ), and a good agreement about pore size is found between TEM data $\left(D_{\text {TEM }}^{\mathrm{p}}=\right.$ $20 \mathrm{~nm})$ and gas sorption data $\left(D_{\mathrm{BJH}}^{\mathrm{p}}=23 \mathrm{~nm}\right)$.

\section{VESICLE TEMPLATING}

By a judicious variation of the packing parameter, which is determined by the relative volume fractions of the stabilizer (PHEA) and core-forming (PS), it is possible through RAFT aqueous dispersion polymerization to synthesize copolymer particles with a higher order morphology. Compared to $\mathrm{PHEA}_{25}-b-\mathrm{PS}_{118}$ latex used as reference (run $a$, Table 2), $\mathrm{PHEA}_{17}-b-\mathrm{PS}_{136}$ (run $k$ ) shows a higher mean DP of the PHEA stabilizer block, while the mean DP of the hydrophobic PS block increases. This leads to an increase of the packing parameter, which accounts for the progressive evolution in copolymer morphology from spheres to vesicles as observed in the TEM image $k 0$ of Figure 11. There is an obvious interest to use such kind of non-spherical templates in mesoporous carbon synthesis since this type of morphology is not achievable by LC mesophases. TEM picture $k$ of mesoporous carbon obtained with this vesicular copolymer nanoobject shows a complex structure, with lighter and darker regions reflecting the morphology of the orginal template. Darker regions display a similar size as voids of vesicular templates 
suggesting the ability of phenolic precursors to cross the PS membrane, fill the vesicle interior and undergo a spatially controlled polymerization. As can be seen in Figure 10, the nitrogen adsorption/desorption isotherm of carbon material $k$ features a coonventional type IV isotherm. The surface area is relatively unchanged $\left(S_{\mathrm{BET}}=683 \mathrm{~m}^{2} \mathrm{~g}^{-1}\right)$ compared with the reference sample a. A sharp $\mathrm{H}_{1}$-type hysteresis is observed, despite difficulties to distinguish mesopores from the TEM picture. A decrease of mesoporous volume $\left(V_{\text {meso }}=0.74 \mathrm{~cm}^{3} \mathrm{~g}^{-1}\right)$ compared with the reference sample $a\left(V_{\text {meso }}=1.01 \mathrm{~cm}^{3} \mathrm{~g}^{-1}\right)$ could reflect a decreased stability of vesicular nanoobjects. Weaker stabilization or morphology change of the copolymer vesicules is also suggested during carbon preparation given that $\mathrm{BJH}$ model reveals an average $D_{\mathrm{BJH}}^{\mathrm{p}}=28 \mathrm{~nm}$, while the starting vesicular nano-objects are characterized by larger sizes and dispersity $\left(D_{\text {TEM }}^{l}=30-170\right.$ $\mathrm{nm})$.

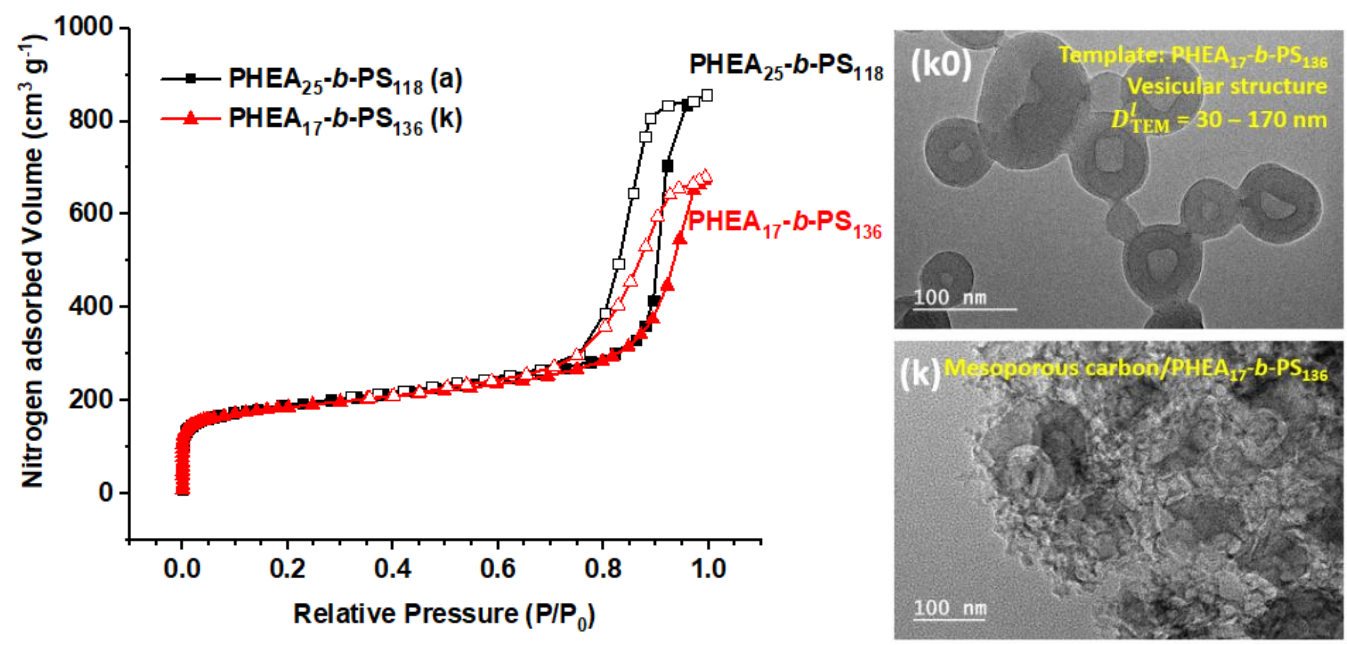

Figure 11. Left: nitrogen adsorption/desorption isotherms of mesoporous carbon prepared from PHEA $_{17}-b$-PS 136 copolymer vesicles. Right: TEM images of the copolymer vesicles $(k O)$ and the corresponding mesoporous carbon $(k)$.

\section{CONCLUSIONS}

This study shows the new potentialities offered by well-defined core-shell PHEA-b-PS nanoparticles as template for the synthesis of mesoporous carbons. Diblock copolymer 
nanoparticles with diameters ranging from 20 to $40 \mathrm{~nm}$ were prepared by an approach combining PISA in dispersion with a controlled RAFT mechanism. Fine tuning of textural properties is achieved by varying template concentration and block DP. Compared with a conventional latex templating approach, a core-shell particle morphology stands out by its ability to provide independent control of mesopore diameter and wall thickness. As replicate of the hydrophobic core, the mesopore size can be adjusted by changing the PS block DP. Wall thickness can be modulated by the spatial extent of the PHEA steric stabilizing layer that will be more extended with a higher DP. The same effect can be reached by decreasing template concentration, thus leading to completely isolated mesopores. Therefore, core-shell PHEA-b-PS nanoparticles prove to be a complex and dual template because it ensures both a conventional transcriptive synthesis thanks to PS core acting as "impenetrable" filler, but also a morphosynthesis through a spatiallycontrolled polymerization in PHEA shell. Finally, we have also reported the synthesis of mesoporous carbon material based on a vesicular template prepared also by PISA that is not achievable using conventional soft templates.

\section{ACKNOWLEDGEMENTS}

We acknowledge Mrs. Bénédicte Réty for performing the thermal annealing treatments and Dr. Jean-Marc Le Meins for the X-ray diffraction analysis.

\section{GLOSSARY}

\begin{tabular}{|l|l|}
\hline Term & Description \\
\hline BET & Brunauer-Emmett-Teller theory \\
\hline BJH & Barrett-Joyner-Halenda method \\
\hline CTA & Chain transfer agent \\
\hline$D_{\text {DLS }}^{l}$ & Diameter of nano-latex determined by DLS technique $\mathrm{nm}$ \\
\hline DLS & Dynamic light scattering \\
\hline
\end{tabular}




\begin{tabular}{|l|l|}
\hline$D_{\text {TEM }}^{l}$ & $\begin{array}{l}\text { Diameter of nano-latex determined on the basis of TEM images with ImageJ } \\
\text { software }\end{array}$ \\
\hline$D P$ & Degree of polymerization \\
\hline$D_{\mathrm{BJH}}^{\mathrm{p}}$ & Pore diameter determined by BJH method \\
\hline$D_{\mathrm{TEM}}^{\mathrm{p}}$ & Pore diameter determined by TEM \\
\hline HEA & Hydroxyethyl acrylate \\
\hline LED & Light-emitting diode \\
\hline$M_{\mathrm{n}}$ & Number-average molar mass \\
\hline$M_{\mathrm{w}}$ & Weight-average molar mass \\
\hline NLDFT & Nonlocal density functional theory \\
\hline PHEA & Poly(hydroxyethyl acrylate) \\
\hline PHEA- $b$-PS & Poly(hydroxyethyl acrylate)-b-polystyrene \\
\hline PISA & Polymerization-induced self-assembly \\
\hline PS & Polystyrene \\
\hline$r$ & Ratio of the concentration of the copolymer to the reference sample $a$ \\
\hline RAFT & Reversible-addition fragmentation-transfer \\
\hline$S_{\mathrm{BET}}$ & Surface area of mesoporous carbons determined by BET theory \\
\hline SDS & Sodium dodecyl sulfate \\
\hline$T_{\mathrm{g}}$ & Glass transition temperature \\
\hline TTC & Trithiocarbonate \\
\hline$V_{\text {meso }}$ & Volume of mesopores in mesoporous carbon material \\
\hline$V_{\text {micro }}$ & Volume of micropores in mesoporous carbon material \\
\hline$V_{\mathrm{T}}$ & Total volume of both micro- and mesopores in mesoporous carbon material \\
\hline$\delta$ & $\begin{array}{l}\text { Estimation of the solvated shell thickness in core-shell particle (Difference } \\
\text { between DLS and TEM-based particle diameters) }\end{array}$ \\
\hline$\delta_{\mathrm{TEM}}^{\mathrm{p}}$ & Wall thickness of mesoporous carbon materials determined by TEM \\
\hline
\end{tabular}

\section{ASSOCIATED CONTENT}

The Supporting Information is available free of charge on the ACS Publications website at DOI: 10.1021/acs.langmuir.9b02062. Additional characterization results include DSC plots of PHEA- $b$-PS based copolymers (Fig. S1), size exclusion chromatography plots of various

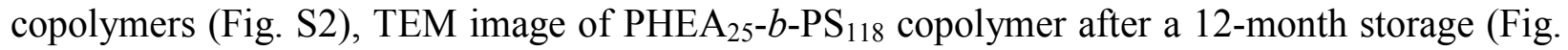
S3), TEM image of a phenolic resin/PHEA $25-b-$ PS $_{118}$ hybrid (Fig. S4), TEM images of copolymer nanoparticles with different DPs (Fig. S5), TEM image of a densely packed array of 
PHEA $_{25}-b-\mathrm{PS}_{118}$ and $\mathrm{PHEA}_{85}-b-\mathrm{PS}_{118}$ nanoparticles (Fig. S6), adsorption/desorption isotherms and TEM images of carbon materials based on PHEA (Fig. S7), pore size distributions of various carbon materials (Fig. S8), tomographic images of carbon templated by PS nanolatex (Fig. S9), properties of carbon materials synthesized using PHEA homopolymer (Table S1), electron tomography tilt series of mesoporous carbons templated by $\mathrm{PHEA}_{25}-b-\mathrm{PS}_{118}$ (Movie S1) and PS latex (Movie S2).

\section{ACKNOWLEDGEMENTS}

French ministry of higher education and research is acknowledged for providing a UHA scholarship to Vitalii Tkachenko.

\section{REFERENCES}

(1) Chai, G. S.; Shin, I. S.; Yu, J.-S. Synthesis of Ordered, Uniform, Macroporous Carbons with Mesoporous Walls Templated by Aggregates of Polystyrene Spheres and Silica Particles for Use as Catalyst Supports in Direct Methanol Fuel Cells. Adv. Mater. 2004, 16 (22), 2057-2061.

(2) Velev, O. D.; Kaler, E. W. Structured Porous Materials via Colloidal Crystal Templating: From Inorganic Oxides to Metals. Adv. Mater. 2000, 12 (7), 531-534.

(3) Holland, B. T.; Blanford, C. F.; Stein, A. Synthesis of Macroporous Minerals with Highly Ordered Three-Dimensional Arrays of Spheroidal Voids. Science 1998, 281 (5376), 538-540.

(4) Antonietti, M.; Berton, B.; Göltner, C.; Hentze, H.-P. Synthesis of Mesoporous Silica with Large Pores and Bimodal Pore Size Distribution by Templating of Polymer Latices. Adv. Mater. 1998, 10 (2), 154-159.

(5) Suib, S. L. A Review of Recent Developments of Mesoporous Materials. Chem. Rec. 2017, 17 (12), 1169-1183.

(6) R. Benzigar, M.; Naidu Talapaneni, S.; Joseph, S.; Ramadass, K.; Singh, G.; Scaranto, J.; Ravon, U.; Al-Bahily, K.; Vinu, A. Recent Advances in Functionalized Micro and Mesoporous Carbon Materials: Synthesis and Applications. Chem. Soc. Rev. 2018, 47 (8), 2680-2721.

(7) Lukens, W. W.; Stucky, G. D. Synthesis of Mesoporous Carbon Foams Templated by Organic Colloids. Chem. Mater. 2002, 14 (4), 1665-1670.

(8) Sonntag, P.; Ayme-Perrot, D.; Simon, J.-M.; Walter, S. Carbon-Based Materials Derived from Latex. US Patent 9017579B2, 2015.

(9) Frank, H.; Ziener, U.; Landfester, K. Synthesis of Different Mesoporous SiO2 Structures by Using PNIPAM-Co-PS Particles as Templates. Macromol. Symp. 2014, 337 (1), 18-24.

(10) Rahrig, D. B. Dynamic Mechanical and Thermal Analysis for the Determination of RFL Morphology. J. Adhes. 1984, 16 (3), 179-215. 
(11) Guo, T.; Zhu, J.; Chen, X.; Song, M.; Zhang, B. Novel Monolithic Mesoporous Foamed Carbons Prepared Using Micro-Colloidal Particles as Templates. J. Non-Cryst. Solids 2007, 353 (30), 2893-2899.

(12) Soll, S.; Antonietti, M.; Yuan, J. Poly(Ionic Liquid) Nanoparticles as Novel Colloidal Template for Silica Nanocasting. Polymer 2014, 55 (16), 3415-3422.

(13) Nunes, J. de S.; Asua, J. M. Theory-Guided Strategy for Nanolatex Synthesis. Langmuir 2012, 28 (19), 7333-7342.

(14) Schmidt-Winkel, P.; Lukens, Wayne W.; Yang, P.; Margolese, D. I.; Lettow, J. S.; Ying, J. Y.; Stucky, G. D. Microemulsion Templating of Siliceous Mesostructured Cellular Foams with Well-Defined Ultralarge Mesopores. Chem. Mater. 2000, 12 (3), 686-696.

(15) Jasinski, F.; Zetterlund, P. B.; Braun, A. M.; Chemtob, A. Photopolymerization in Dispersed Systems. Prog. Polym. Sci. 2018, 84, 47-88.

(16) Liu, Y.; Goebl, J.; Yin, Y. Templated Synthesis of Nanostructured Materials. Chem. Soc. Rev. 2013, 42 (7), 2610-2653.

(17) Li, W.; Liu, J.; Zhao, D. Mesoporous Materials for Energy Conversion and Storage Devices. Nat. Rev. Mater. 2016, 1 (6), 16023.

(18) Xin, W.; Song, Y. Mesoporous Carbons: Recent Advances in Synthesis and Typical Applications. RSC Adv. 2015, 5 (101), 83239-83285.

(19) Deng, Y.; Wei, J.; Sun, Z.; Zhao, D. Large-Pore Ordered Mesoporous Materials Templated from Non-Pluronic Amphiphilic Block Copolymers. Chem Soc Rev 2013, 42 (9), 4054-4070.

(20) Libbrecht, W.; Verberckmoes, A.; Thybaut, J. W.; Van Der Voort, P.; De Clercq, J. Tunable Large Pore Mesoporous Carbons for the Enhanced Adsorption of Humic Acid. Langmuir 2017, 33 (27), 6769-6777.

(21) Wei, J.; Sun, Z.; Luo, W.; Li, Y.; Elzatahry, A. A.; Al-Enizi, A. M.; Deng, Y.; Zhao, D. New Insight into the Synthesis of Large-Pore Ordered Mesoporous Materials. J. Am. Chem. Soc. 2017, 139 (5), 1706-1713.

(22) Liu, C.; Yu, M.; Li, Y.; Li, J.; Wang, J.; Yu, C.; Wang, L. Synthesis of Mesoporous Carbon Nanoparticles with Large and Tunable Pore Sizes. Nanoscale 2015, 7 (27), 1158011590.

(23) Tang, J.; Liu, J.; Li, C.; Li, Y.; Tade, M. O.; Dai, S.; Yamauchi, Y. Synthesis of Nitrogen-Doped Mesoporous Carbon Spheres with Extra-Large Pores through Assembly of Diblock Copolymer Micelles. Angew. Chem. Int. Ed. 2014, 588-593.

(24) Guo, Z.; Zhou, D.; Dong, X.; Qiu, Z.; Wang, Y.; Xia, Y. Ordered Hierarchical Mesoporous/Macroporous Carbon: A High-Performance Catalyst for Rechargeable Li-O 2 Batteries. Adv. Mater. 2013, 25 (39), 5668-5672.

(25) Deng, Y.; Yu, T.; Wan, Y.; Shi, Y.; Meng, Y.; Gu, D.; Zhang, L.; Huang, Y.; Liu, C.; Wu, X.; et al. Ordered Mesoporous Silicas and Carbons with Large Accessible Pores Templated from Amphiphilic Diblock Copolymer Poly(Ethylene Oxide)- b-Polystyrene. J. Am. Chem. Soc. 2007, 129 (6), 1690-1697.

(26) Luo, W.; Zhao, T.; Li, Y.; Wei, J.; Xu, P.; Li, X.; Wang, Y.; Zhang, W.; Elzatahry, A. A.; Alghamdi, A.; et al. A Micelle Fusion-Aggregation Assembly Approach to Mesoporous Carbon Materials with Rich Active Sites for Ultrasensitive Ammonia Sensing. J. Am. Chem. Soc. 2016, 138 (38), 12586-12595. 
(27) Deng, Y.; Cai, Y.; Sun, Z.; Gu, D.; Wei, J.; Li, W.; Guo, X.; Yang, J.; Zhao, D. Controlled Synthesis and Functionalization of Ordered Large-Pore Mesoporous Carbons. Adv. Funct. Mater. 2010, 20 (21), 3658-3665.

(28) Tkachenko, V.; Ghimbeu, C. M.; Vaulot, C.; Vidal, L.; Poly, J.; Chemtob, A. RAFTPhotomediated PISA in Dispersion: Mechanism, Optical Properties and Application in Templated Synthesis. Polym. Chem. 2019, 10 (18), 2316-2326.

(29) Canning, S. L.; Smith, G. N.; Armes, S. P. A Critical Appraisal of RAFT-Mediated Polymerization-Induced Self-Assembly. Macromolecules 2016, 49 (6), 1985-2001.

(30) Wang, X.; An, Z. New Insights into RAFT Dispersion Polymerization-Induced SelfAssembly: From Monomer Library, Morphological Control, and Stability to Driving Forces. Macromol. Rapid Commun. 2019, 40 (2), 1800325.

(31) Musyanovych, A.; Landfester, K. Core-Shell Particles. In Macromolecular Engineering; John Wiley \& Sons, Ltd, 2011; pp 1209-1247.

(32) Gosecka, M.; Gosecki, M. Characterization Methods of Polymer Core-Shell Particles. Colloid Polym. Sci. 2015, 293 (10), 2719-2740.

(33) Tadros, T. Electrostatic and Steric Stabilization of Colloidal Dispersions. In Electrical Phenomena at Interfaces and Biointerfaces; John Wiley \& Sons, Ltd, 2012; pp 153-172.

(34) Zhang, Y.; Wang, Z.; Matyjaszewski, K.; Pietrasik, J. Versatile PISA Templates for Tailored Synthesis of Nanoparticles. Eur. Polym. J. 2019, 110, 49-55.

(35) Ghimbeu, C. M.; Vidal, L.; Delmotte, L.; Meins, J.-M. L.; Vix-Guterl, C. Catalyst-Free Soft-Template Synthesis of Ordered Mesoporous Carbon Tailored Using Phloroglucinol/Glyoxylic Acid Environmentally Friendly Precursors. Green Chem. 2014, 16 (6), 3079-3088.

(36) Maetz, A.; Delmotte, L.; Moussa, G.; Dentzer, J.; Knopf, S.; Matei Ghimbeu, C. Facile and Sustainable Synthesis of Nitrogen-Doped Polymer and Carbon Porous Spheres. Green Chem. 2017, 19 (9), 2266-2274.

(37) Forney, B. S.; Guymon, C. A. Nanostructure Evolution during Photopolymerization in Lyotropic Liquid Crystal Templates. Macromolecules 2010, 43, 8502-8510.

(38) Gregg, S. J.; Sing, K. S. W. Adsorption, Surface Area and Porosity Academic. In Adsorption, surface area and porosity academic; Academic Press: London, 1982; p 111.

(39) Grosman, A.; Ortega, C. Capillary Condensation in Porous Materials. Hysteresis and Interaction Mechanism without Pore Blocking/Percolation Process. Langmuir 2008, 24 (8), 3977-3986.

(40) Meng, Y.; Gu, D.; Zhang, F.; Shi, Y.; Yang, H.; Li, Z.; Yu, C.; Tu, B.; Zhao, D. Ordered Mesoporous Polymers and Homologous Carbon Frameworks: Amphiphilic Surfactant Templating and Direct Transformation. Angew. Chem. Int. Ed. 2005, 44 (43), 7053-7059.

(41) Kruk, M.; Dufour, B.; Celer, E. B.; Kowalewski, T.; Jaroniec, M.; Matyjaszewski, K. Well-Defined Poly(Ethylene Oxide)-Polyacrylonitrile Diblock Copolymers as Templates for Mesoporous Silicas and Precursors for Mesoporous Carbons. Chem. Mater. 2006, 18 (6), 14171424.

(42) Ravikovitch, P. I.; Neimark, A. V. Experimental Confirmation of Different Mechanisms of Evaporation from Ink-Bottle Type Pores: Equilibrium, Pore Blocking, and Cavitation. Langmuir 2002, 18 (25), 9830-9837.

(43) Ravikovitch, P. I.; Neimark, A. V. Density Functional Theory of Adsorption in Spherical Cavities and Pore Size Characterization of Templated Nanoporous Silicas with Cubic and ThreeDimensional Hexagonal Structures. Langmuir 2002, 18 (5), 1550-1560. 
(44) Thommes, M. Physical Adsorption Characterization of Nanoporous Materials. Chem. Ing. Tech. 2010, 82 (7), 1059-1073.

(45) Thommes, M.; Kaneko, K.; Neimark, A. V.; Olivier, J. P.; Rodriguez-Reinoso, F.; Rouquerol, J.; Sing, K. S. W. Physisorption of Gases, with Special Reference to the Evaluation of Surface Area and Pore Size Distribution (IUPAC Technical Report). Pure Appl. Chem. 2015, 87 (9-10), 1051-1069.

(46) Everett, D. Basic Principles of Colloid Science; Royal Soc. Chem.:London, U.K., 1988. 
For Table of Contents only

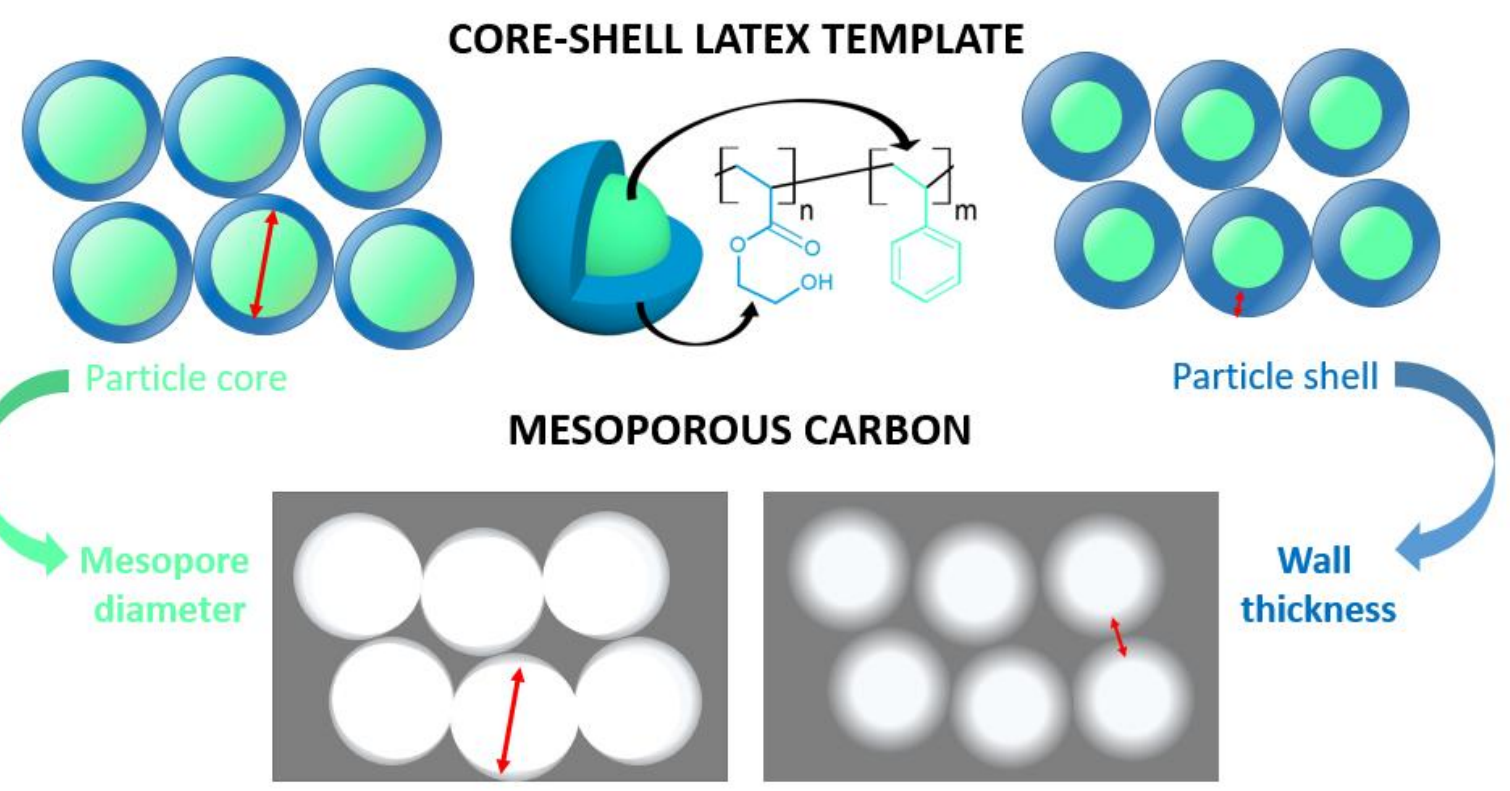

